\title{
Satellite-detected fluorescence reveals global physiology of ocean phytoplankton
}

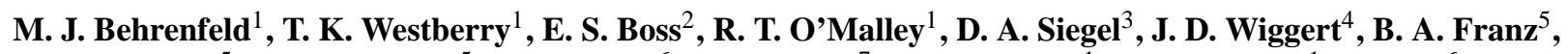

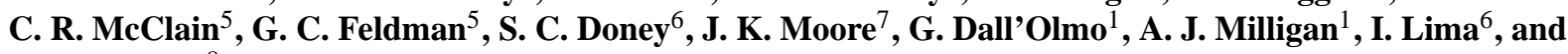 \\ N. Mahowald ${ }^{8}$ \\ ${ }^{1}$ Dept. of Botany and Plant Pathology, Cordley Hall 2082, Oregon State University, Corvallis, OR 97331-2902, USA \\ ${ }^{2}$ School of Marine Sciences, 5706 Aubert Hall, University of Maine, Orono, Maine 04469-5741, USA \\ ${ }^{3}$ Institute for Computational Earth System Science and Department of Geography, University of California, Santa Barbara, \\ CA 93106-3060, USA \\ ${ }^{4}$ Dept. of Marine Sciences, University of Southern Mississippi, 1020 Balch Blvd., Stennis Space Center, \\ MS 39529-9904, USA \\ ${ }^{5}$ NASA Goddard Space Flight Center, Greenbelt, MD 20771, USA \\ ${ }^{6}$ Dept. of Marine Chemistry and Geochemistry, Woods Hole Oceanographic Institution Woods Hole, MA 02543-1543 \\ ${ }^{7}$ Dept. of Earth System Science, 3214 Croul Hall, University of California, Irvine, CA 92697-3100, USA \\ ${ }^{8}$ Cornell University, 2140 Snee Hall, Ithaca, NY, USA, 14850, USA
}

Received: 28 August 2008 - Published in Biogeosciences Discuss.: 5 November 2008

Revised: 2 April 2009 - Accepted: 6 April 2009 - Published: 8 May 2009

\begin{abstract}
Phytoplankton photosynthesis links global ocean biology and climate-driven fluctuations in the physical environment. These interactions are largely expressed through changes in phytoplankton physiology, but physiological status has proven extremely challenging to characterize globally. Phytoplankton fluorescence does provide a rich source of physiological information long exploited in laboratory and field studies, and is now observed from space. Here we evaluate the physiological underpinnings of global variations in satellite-based phytoplankton chlorophyll fluorescence. The three dominant factors influencing fluorescence distributions are chlorophyll concentration, pigment packaging effects on light absorption, and light-dependent energy-quenching processes. After accounting for these three factors, resultant global distributions of quenching-corrected fluorescence quantum yields reveal a striking consistency with anticipated patterns of iron availability. High fluorescence quantum yields are typically found in low iron waters, while low quantum yields dominate regions where other environmental factors are most limiting to phytoplankton growth. Specific properties of photosynthetic membranes are discussed that provide a mechanistic view linking iron stress to satellite-
\end{abstract}

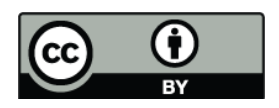

Correspondence to: M. Behrenfeld (mjb@science.oregonstate.edu) detected fluorescence. Our results present satellite-based fluorescence as a valuable tool for evaluating nutrient stress predictions in ocean ecosystem models and give the first synoptic observational evidence that iron plays an important role in seasonal phytoplankton dynamics of the Indian Ocean. Satellite fluorescence may also provide a path for monitoring climate-phytoplankton physiology interactions and improving descriptions of phytoplankton light use efficiencies in ocean productivity models.

\section{Introduction}

Phytoplankton are taxonomically-diverse, single-celled organisms that populate the upper sunlit layer of nearly all water bodies on Earth, and they are photosynthetic. Net annual photosynthesis by ocean phytoplankton alone is of similar magnitude as that by all terrestrial plants (Field et al., 1998; Behrenfeld et al. 2001) and it plays a vital role in biospheric carbon cycling. Ocean productivity is strongly impacted by climate variations (Gregg et al., 2005; Behrenfeld et al., 2006a), but quantifying this impact and predicting future change requires an understanding of environmental factors regulating phytoplankton light use efficiencies and growth (Behrenfeld et al., 2008). However, globally characterizing physiological variability has proven far more

Published by Copernicus Publications on behalf of the European Geosciences Union. 
challenging than simply quantifying phytoplankton standing stocks. In 2002, the Moderate-resolution Imaging Spectroradiometer (MODIS) sensor was launched on NASA's Aqua satellite platform with a capacity to detect phytoplankton chlorophyll fluorescence for assessing phytoplankton physiological status.

As with terrestrial plants, oxygenic photosynthesis in phytoplankton involves light harvesting and electron transport between two pigmented reaction centers: photosystem II (PSII), which is solely responsible for oxygen evolution, and photosystem I (PSI), where light energy is captured in chemical form. Both photosystems contribute to cellular chlorophyll concentration and light absorption, but in vivo fluorescence emanates almost exclusively from PSII (Falkowski and Kiefer, 1985). Artificially stimulated fluorescence has accordingly been used as a non-invasive probe for studying phytoplankton and PSII functioning (e.g., Lorenzen, 1966; Kiefer, 1973 a, b; Loftus and Seliger, 1975; Vincent, 1979; Cullen, 1982; Cleveland and Perry, 1987; Krause and Weis, 1991; Falkowski and Kolber, 1995; Behrenfeld et al., 2006b). Fluorescence emission under natural sunlight is also detectable in subsurface- and above-surface upwelling irradiance spectra (Neville and Gower, 1977; Morel and Prieur, 1977). Incident irradiance and pigment absorption strongly influence this "natural fluorescence" signal (e.g., Babin et al., 1996; Cullen et al., 1997; Ostrowska et al., 1997; Maritorena et al., 2000; Morrison, 2003; Westberry et al., 2003; Laney et al., 2005; Huot et al., 2007; Schallenberg et al., 2008), which was proposed originally as a tool for deriving phytoplankton photosynthetic rates (Topliss and Platt, 1986; Kiefer et al., 1989) and can register physiological variability (Letelier et al., 1997; Morrison, 2003). Such field observations were instrumental to the development of satellite fluorescence detection capabilities.

To date, application of satellite chlorophyll fluorescence observations has been limited and largely focused on geographically-restricted studies assessing near-shore chlorophyll concentrations or detecting harmful algal species (e.g., Gower et al., 2004; Hu et al., 2005; Ahn and Shanmugam, 2007; Gilerson et al., 2007; Gower and King, 2007; Huot et al., 2007; Gilerson et al., 2008 - but see also Huot et al., 2005). Here, satellite-based chlorophyll fluorescence data are presented at their full global scale and evaluated as a physiological indicator. We find that three primary factors regulate global phytoplankton fluorescence distributions: (1) pigment concentrations, (2) a photoprotective response aimed at preventing high-light damage (i.e., "nonphotochemical quenching", NPQ), and (3) "pigment packaging", a self-shading phenomenon influencing light absorption efficiencies (Duysens 1956; Bricaud et al., 1995, 1998). This result is consistent with earlier findings (e.g., Babin et al., 1996; Gower et al., 2004; Gower and King, 2007; Huot et al., 2007). We account for these three primary factors and derive additional information on nutrient stressors through global distributions of NPQ-normalized fluorescence quan- tum yields. Iron stress is found to be a key factor influencing satellite-based quantum yields, consistent with physiological investigations of iron stress effects (Sakshaug and Holm-Hansen, 1977; Rueter and Ades, 1987; Behrenfeld et al., 2006b, 2008). These results indicate that satellite fluorescence quantum yields may prove an important new tool for characterizing iron stress in the global oceans, improving ocean photosynthesis estimates, and resolving climatephytoplankton interactions.

\section{Data and analyses}

\subsection{Fluorescence from space}

Chlorophyll fluorescence $(F)$ is a minor de-excitation pathway for sunlight energy absorbed by phytoplankton, but it creates a distinct peak in the color spectrum of the ocean (Neville and Gower, 1977). This flux of fluoresced light is readily resolved in field radiance data and is frequently modeled as the product of chlorophyll concentration $(C h l)$, the spectrally-averaged, chlorophyll-specific phytoplankton absorption coefficient $\left(<a_{p h}^{*}>\right)$, the flux of photosynthetically active radiation $(i P A R)$, and the quantum yield of fluorescence $(\phi)$ (e.g., Kiefer et al., 1989; Babin et al., 1996):

$F=C h l \times<a_{\mathrm{ph}}^{*}>\times i P A R \times \phi$

Equation (1) highlights fundamental dependencies of solarinduced fluorescence emission, but additional factors must be considered when extracting the phytoplankton fluorescence signal from space (Huot et al., 2005). Here, an overview is given on our treatment of MODIS satellite fluorescence data, while a detailed step-wise description is provided in Appendix A.

Global open-ocean phytoplankton chlorophyll fluorescence $\left(F_{\text {sat }}\right)$ distributions were investigated using standard monthly MODIS-Aqua fluorescence line height products generated by NASA's ocean color processing group (http://oceancolor.gsfc.nasa.gov) for the period January 2003 to December 2007. Radiances measured by the $10 \mathrm{~nm}$-wide fluorescence band on MODIS include both atmospheric and oceanic components, cover only a portion of the chlorophyll fluorescence emission spectrum, and are centered at $678 \mathrm{~nm}$ rather than the emission peak at $685 \mathrm{~nm}$ (to avoid an atmospheric oxygen absorption feature). The atmospheric component is removed during standard processing using measurement bands in the near-infrared (Gordon and Wang, 1994). The residual oceanic component of the fluorescence band signal includes contributions from chlorophyll fluorescence and backscattered and Raman scattered sunlight. The two latter components (backscatter and Raman) are accounted for by calculating a $678 \mathrm{~nm}$ "baseline radiance" through linear interpolation of radiances measured at 667 and $748 \mathrm{~nm}$ (Abbott and Letelier, 1999; Huot et al., 2005). Subtraction of this "baseline" from the $678 \mathrm{~nm}$ signal yields the fluorescence line height product (Appendix A). 
Conversion of fluorescence line height data into $F_{\text {sat }}$ requires additional adjustments accounting for satellite viewing geometry, attenuation in the water column of downwelling solar radiation and upwelled fluoresced light, differences between the MODIS fluorescence detection band and the chlorophyll emission spectrum, the fraction of isotropically emitted fluorescence propagating in the upward direction, and the top-of-atmosphere irradiance (as detailed in Appendix A). Combining these corrections into a single term $(S)$, a simplified expression emerges relating global satellite fluorescence $\left(F_{\text {sat }}\right)$ to four primary variables:

$F_{\text {sat }}=C h l_{\text {sat }} \times<a_{p h}^{*}>\times \phi \times S$,

where $C h l_{\text {sat }}$ is satellite-derived surface-layer chlorophyll concentration and $S$ is approximately $100 \mathrm{~mW} \mathrm{~cm}^{-2} \mu \mathrm{m}^{-1} \mathrm{sr}^{-1} \mathrm{~m}$ (Appendix A).

A critical distinction between Eqs. (1) and (2) is that the latter does not include $i P A R$. This difference results because fluorescence line height data used for calculating $F_{\text {sat }}$ are derived from radiances normalized to the downwelling light at the sea surface i.e., "normalized water leaving radiance": $L_{W N}(\lambda)$. Consequently, the direct dependence of $F_{\text {sat }}$ on $i P A R$ is already accounted for (Appendix A). This property of line height products was earlier overlooked in the processing of MODIS data, resulting in an incorrect additional division by $i P A R$ in quantum yield calculations. A second important development in our analysis was the treatment of negative fluorescence values. In earlier studies, these negative values were eliminated by adding an arbitrary fluorescence constant. This "constant" impacted $\phi$ estimates in low chlorophyll waters, initially having a value equal to the fluorescence of $1 \mathrm{mg} \mathrm{Chl} \mathrm{m}{ }^{-3}$ (Abbott and Letelier, 1999) and later revised downward (Huot et al., 2005). We do not add an arbitrary constant. Instead, we removed the negative pixels because they represented only $0.2 \%$ of the MODIS data, are randomly distributed globally, and likely represent pixels with unflagged atmospheric correction problems. Finally, we imposed the first-principles constraint that $F_{\text {sat }}=$ 0 when $C h l_{\text {sat }}=0$ (i.e., there can be no chlorophyll fluorescence when there is no chlorophyll). Regression analysis of $F_{\text {sat }}$ on $C h l_{\text {sat }}$ indicates that this constraint is satisfied by subtracting a small value of $0.001 \mathrm{~mW} \mathrm{~cm}{ }^{-2} \mu m^{-1} \mathrm{sr}^{-1}$ from $F_{\text {sat }}$, which is well within the radiometric uncertainty of $\pm 0.003 \mathrm{~mW} \mathrm{~cm}^{-2} \mu \mathrm{m}^{-1} \mathrm{sr}^{-1}$ for the MODIS fluorescence band (see: http://oceancolor.gsfc.nasa.gov/VALIDATION/ operational_gains.html).

\subsection{Global nutrient fields}

To investigate relationships with nutrient stressors, fluorescence quantum yields calculated from $F_{\text {sat }}$ data were initially compared to surface nitrate and phosphate climatologies from the World Ocean Atlas (Garcia et al., 2006) and global distributions of modeled aeolian soluble iron deposition. Deposition of soluble iron was estimated using a

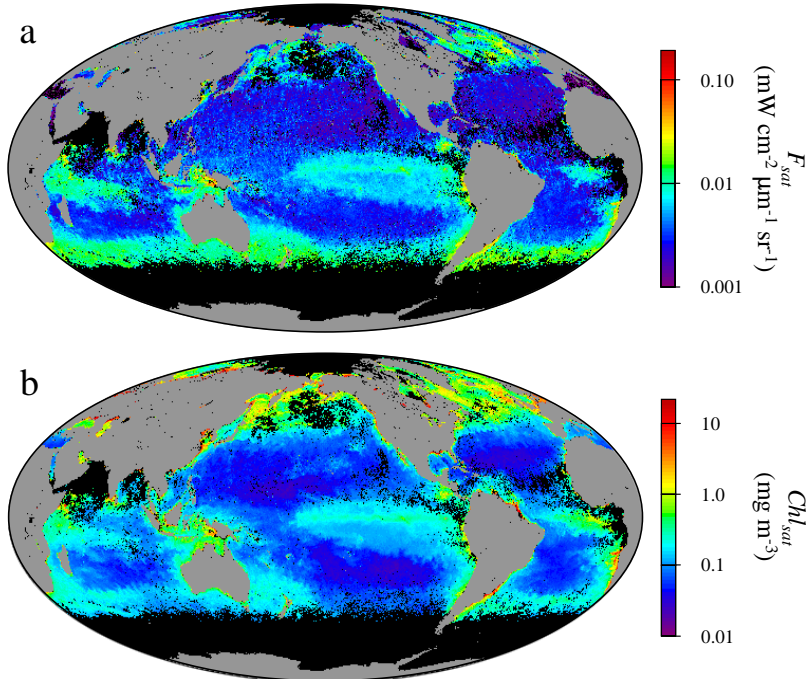

Fig. 1. July 2004 examples of global monthly average MODIS (a) $F_{\text {sat }}$ and (b) $C h l_{\text {sat }}$. Chlorophyll concentrations are based on the standard NASA OC-3 algorithm.

three-dimensional model of dust entrainment, transport, deposition, and solubility (Luo et al., 2003; Mahowald et al., 2003; Luo et al., 2008). The model is driven by reanalysis winds from the National Center for Environmental Prediction/National Center for Atmospheric Research (Kistler et al., 2001) that represent a combination of observations and model output for a given time period. Entrainment of dust into the atmosphere is simulated using the Dust Entrainment and Deposition module (Zender et al., 2003), while removal is through wet and dry deposition processes. Compared to observations, the model does well in simulating dust cycles in most regions, but may yield an overestimate of dust deposition in some remote Southern Hemisphere ocean regions based on comparisons with the few measurements available (Luo et al., 2003; Wagener et al., 2008). This overestimate of deposition may be partially compensated for, however, by an underestimate of the soluble iron fraction in remote regions (Luo et al., 2005; Luo et al., 2008).

\section{Results and discussion}

\subsection{Factors dominating satellite fluorescence}

Spatial patterns in $F_{\text {sat }}$ are correlated to first order with $C h l_{\text {sat }}$ (Neville and Gower, 1977; Gower and Borstad, 1990), as illustrated in Fig. 1 using July 2004 images. Thus, $F_{\text {sat }}$ is high wherever surface nutrient levels are sufficient to support significant phytoplankton biomass (thus, enhanced chlorophyll), such as in equatorial and coastal upwelling waters and at high latitudes of the North Atlantic and Southern Ocean (Fig. 1). Conversely, both $F_{\text {sat }}$ and $C h l_{\text {sat }}$ are persistently low 

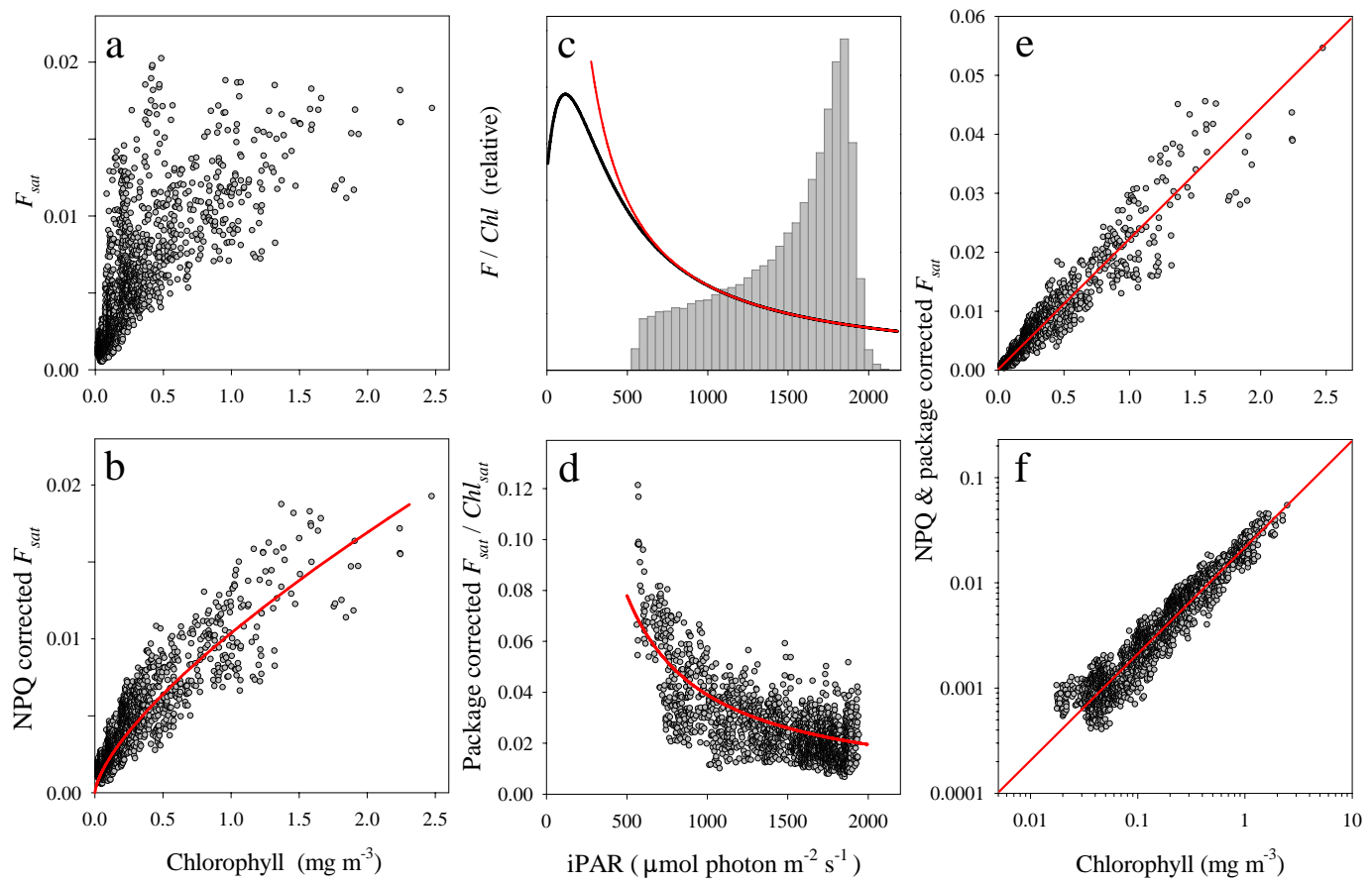

Fig. 2. Primary factors regulating global $F_{\text {sat }}$ distributions over the 5 year MODIS record. (a) Relationship between binned $C h l_{\text {sat }}$ and $F_{\text {sat }}$ (see Appendix A, Fig. A1 for bin designations) (b) Relationship between $C h l_{\text {sat }}$ and NPQ-corrected $F_{\text {sat }}\left(=F_{\text {sat }} \times \overline{i P A R} / i P A R\right.$ ). Curvature reflects pigment packaging effects, which closely follow published changes in $\left\langle a_{p h}\right\rangle$ (red line) (Bricaud et al., 1998) (Appendix A). (c) Conceptual relationship between chlorophyll-specific fluorescence and $i P A R$ (black curve) (see also text and Fig. 3), illustrating the strong decrease in fluorescence yield at high light due to NPQ. Red line $=$ scaled $1 / i P A R$ relationship. Gray bars $=$ frequency histogram for MODIS $i P A R$. (d) Observed relationship between $i P A R$ and chlorophyll-specific $F_{\text {sat }}$ corrected for packaging effects (package correction $=$ $<a_{p h}^{*}>/<\overline{a_{p h}^{*}}>$, where chlorophyll-specific absorption is calculated spectrally over the 400 to $700 \mathrm{~nm}$ band following Babin et al. (1996) and $<\overline{a_{p h}^{*}}>$ is the value of $<a_{p h}^{*}>$ for the global average $C h l_{\text {sat }}$ of $0.134 \mathrm{mg} \mathrm{m}^{-3}=0.0302 \mathrm{~m}^{-1}$ ). Red line $=$ scaled ${ }^{1} / i P A R$ relationship (e) Relationship between $C h l_{\text {sat }}$ and $F_{\text {sat }}$ corrected for NPQ- and pigment packaging $(r=0.96)$. (f) Same as panel e, except with logtransformed axes (see also Appendix A, Fig. A2). Fluorescence units for panels b, c, e, and $\mathrm{f}$ are $\mathrm{mW} \mathrm{cm}{ }^{-2} \mu \mathrm{m}^{-1} \mathrm{sr}^{-1}$. Fluorescence units for panel $\mathrm{d}$ are $\mathrm{mW} \mathrm{cm}{ }^{-2} \mu \mathrm{m}^{-1} \mathrm{sr}^{-1}\left(\mathrm{mg} \mathrm{chl} \mathrm{m}^{-3}\right)^{-1}$.

in the nutrient-impoverished, permanently stratified central ocean gyres (Fig. 1). However, the relationship between $F_{\text {sat }}$ and $C h l_{\text {sat }}$ is not globally consistent. The extent of this variability becomes clear when monthly satellite data for our 5-year MODIS record are aggregated into regional bins (Fig. 2a) (Appendix A, Fig. A1). This variability in the $F_{\text {sat }}$ versus $C h l_{\text {sat }}$ relationship reflects variations in the remaining terms of Eq. (2), particularly $<a_{p h}^{*}>$ and $\phi$. If nutrient stressors impose a detectable physiological signal in $F_{\text {sat }}$ data, retrieving this information requires first an accounting of variability in $<a_{p h}^{*}>$ and primary nutrient-insensitive factors influencing $\phi$.

A prominent phenomenon influencing phytoplankton absorption coefficients $\left(<a_{p h}^{*}>\right)$ is "pigment packaging", which refers to the reduction in $\left.<a_{p h}^{*}\right\rangle$ with increasing chlorophyll levels (Duysens 1956; Bricaud et al., 1995, 1998). Pigment packaging causes a curvilinear relationship between fluorescence and chlorophyll (red line in Fig. 2b) because fluorescence is proportional to light absorption, not simply pigment concentration (Babin et al., 1996; Gower et al., 2004; Huot et al., 2005). The influence of pigment packaging on $F_{\text {sat }}$ can be accounted for using spectrally-resolved (400-700 nm) absorption coefficients, $a_{p h}^{*}(\lambda)$ (Bricaud et al., 1998), following the approach of Babin et al. (1996) (Appendix A).

A key factor influencing fluorescence quantum yields $(\phi)$ is short-term responses to changing incident light level $(i P A R)$. Consider a phytoplankton population growing at steady-state and acclimated to a given growth irradiance. Exposure of these phytoplankton to increasing $I P A R$ will result in a linear increase in absorbed light energy (blue line in Fig. 3a). In constrast, absorbed light energy used for charge separation and photosynthetic $\mathrm{O}_{2}$ evolution (i.e., photochemistry) saturates. At very low light levels, a small fraction of absorbed light energy is lost as fluorescence, the majority of which arises from the core of PSII (Govindjee, 2004) (here, the "core" is taken as proteins CP43, CP47, D1, D2, and the chlorophylls bound to these proteins). As 
photochemistry saturates, this fluorescence loss increases (green line in Fig. 3a - see caption for details). The total photon energy dissipated as fluorescence is, however, a small fraction of total absorbed energy at all light levels. Thus, when phytoplankton are exposed to super-saturating light levels, additional processes must be invoked to dissipate the excess energy and thereby minimize photodamage. These processes are collectively termed "nonphotochemical quenching" (NPQ) (Krause and Weis, 1991; Müller et al., 2001) and they dissipate excess absorbed light energy as heat. An accounting for NPQ is important for $F_{\text {sat }}$ analyses because MODIS data are only collected under near-noon, clearsky conditions when incident sunlight is maximal and supersaturating ( $i P A R$ during MODIS observations ranges from 500 to $2100 \mu$ mole photons $\mathrm{m}^{-2} \mathrm{~s}^{-1}$, Fig. 2c).

Two primary modes of NPQ are antennae quenching (qE) and reaction center quenching (qI) (Morrison, 2003; Krause and Jahns, 2004). Antennae quenching functions by intercepting energy transfer from the outer antennae to the PSII core (Bruce and Vasil'ev, 2004), while qI is associated with damaged or down-regulated PSII and heat dissipation at the core (Kok, 1956; Kyle, 1987; Barber, 1991, 1992; Prasil et al., 1992; Osmond, 1994; Behrenfeld et al., 1998). Together, $\mathrm{qE}$ and $\mathrm{qI}$ account for absorbed light energy in excess of that needed for photochemistry and not lost as fluorescence. Since these NPQ processes do not entail light emission, they are associated with a reduction in $\phi$. If $\mathrm{qE}$ is the dominant NPQ response to variations in $i P A R$ (i.e., we assume a constant fraction of functional PSII centers - see additional discussion below), fluorescence emission should be essentially constant over saturating values of $i P A R$ (green line in Fig. 3a). Under such conditions, NPQ-driven reductions in $\phi$ (gray line in Fig. $3 \mathrm{a}=$ green line divided by the blue line, relative y-axes) are closely approximated by an inverse function of light $\left({ }^{1} /{ }_{i P A R}\right)$ at supersaturating light levels (red line in Figs. 2c, 3a, b), which can be used as a first-order correction for NPQ in $F_{\text {sat }}$ data.

Light-dependent changes in $\phi$ were earlier described by the model of Morrison (2003) and, for a given value of qI, are similar to those shown in Figs. $2 \mathrm{c}$ and $3 \mathrm{a}$ over the range of high-light levels relevant to satellite analysis (gray bars in Fig. 3). In this earlier study, however, $\phi$-iPAR relationships were plotted using log-transformed $i P A R$ data to emphasize variations in $\phi$ at low light, so a comparable illustration is provided here in Fig. 3b. One of the differences with the Morrison (2003) approach is that an NPQinsensitive residual fluorescence was assumed (Morrison's " $r$ " term), whereas here we assume $r=0$. Our description also assumes that total fluorescence emission is invariant at high light levels (Fig. 3a). In contrast, Laney et al. (2005) found chlorophyll-normalized fluorescence to increase with increasing $i P A R$ for natural phytoplankton populations in the Gulf of Alaska. However, the observed rate of fluorescence increase was not proportional to the increase in $i P A R$, with fluorescence rising on average by a factor of only $\sim 1.5$ over
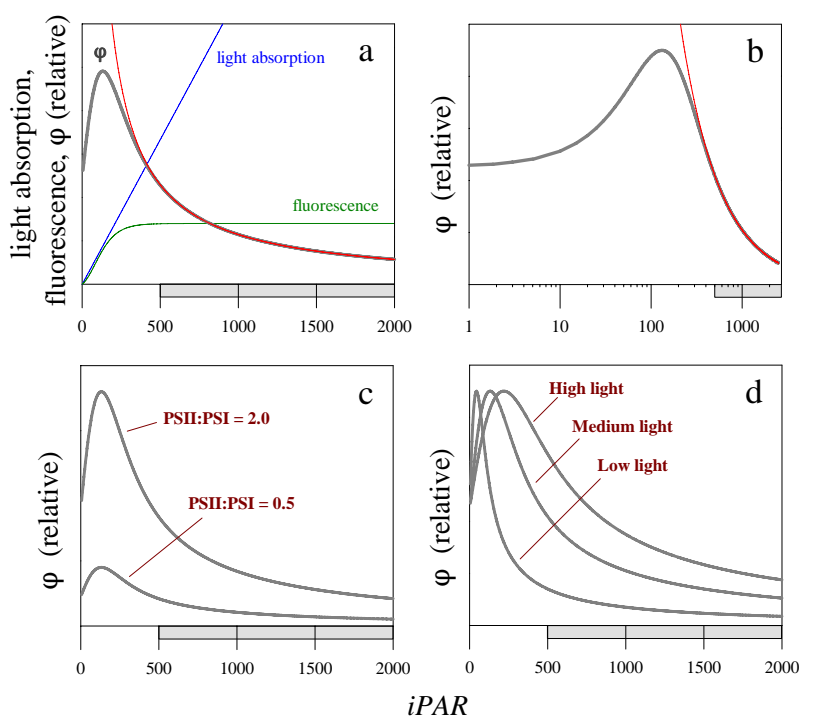

Fig. 3. Relationships between fluorescence quantum yield $(\phi)$ and incident light (iPAR). (a) Changes in $\phi$ with $i P A R$ for phytoplankton acclimated to their light environment. Absorbed light energy delivered to PSII core complexes is described as a saturating function of $i P A R$ using the hyperbolic tangent model of Jassby and Platt (1976) (form: $A=B \tanh \left(\frac{i P A R \times C}{B}\right)$, where $A=$ energy delivered to PSII, $B=$ light saturated rate, and $C=$ initial slope). The fraction of energy lost as fluorescence increases from an initial value to a lightsaturated value corresponding to a normalized fluorescence yield $\left(\mathrm{F}_{\mathrm{v}} / \mathrm{F}_{\mathrm{m}}\right)$ of 0.65 . Green line $=$ fluorescence emission (relative). Blue line $=$ absorbed light energy (relative). Gray line $=\phi=$ green line divided by blue line. Red line $=$ scaled $1 / i P A R$ function. (b) Same $\phi$ data as in panel (a) but plotted against a log-transformed $I P A R$ axis. Red line $=$ scaled ${ }^{1} /{ }_{i P A R}$ function. (c) Change in the $\phi-i P A R$ relationship corresponding to a PSII:PSI ratio shift from 0.5 to 2.0, assuming that pigment distribution between the two photosystems varies in proportion to their relative abundances. Changes in PSII reaction center quenching (qI) result in a similar "whole curve" shift in the $\phi-i P A R$ relationship. (d) Changes in the $\phi-i P A R$ relationship resulting from photoacclimation to different light levels (the three curves correspond to light-saturation levels $\left(\mathrm{E}_{k}\right)$ of 50, 150, and $250 \mu \mathrm{mol}$ photon $\mathrm{m}^{-2} \mathrm{~d}^{-1}$ ). Phytoplankton grown at low-light become light saturated at low $i P A R$ levels and then exhibit strong NPQ upon exposure to higher $i P A R$ levels (lower curve). Higherlight acclimated phytoplankton require higher light levels to saturate photosynthesis and engage NPQ (middle and upper curves). For any one of these three curves, the reduction in $\phi$ from NPQ at supersaturating light levels follows an inverse function of $i P A R$. However, the NPQ effect at any particular saturating $I P A R$ level is stronger in the lower-light acclimated phytoplankton than in the higher-light acclimated cells. This dependence of NPQ on photoacclimation state implies that a single, globally-applied inverse-light function will tend to under-correct for NPQ at high $i P A R$ and overcompensate for NPQ at low $i P A R$ if photoacclimation is positively correlated with $i P A R$ (as occurs with changes in latitude). (a-d) Gray bar on x-axis indicates $i P A R$ range for MODIS fluorescence measurements. For each panel, we assume that $\mathrm{qI}$ is constant. 
an $i P A R$ range of 400 to $1800 \mu \mathrm{mol}$ quanta $\mathrm{m}^{-2} \mathrm{~s}^{-1}$. Consequently, calculated $\phi$ values for the Laney et al. (2005) data follow a relationship similar to an inverse $i P A R$ function, but with a somewhat shallower slope (data not shown).

The $<a_{p h}^{*}>$ correction of Babin et al. (1996) and the inverse light function described here permit adjustment of $F_{\text {sat }}$ for pigment packaging and NPQ effects, respectively. The influence of these two factors is clearly expressed in our binned MODIS data (Fig. 2, A1). For pigment packaging, comparison of NPQ-corrected $F_{\text {sat }}$ with $C h l_{\text {sat }}$ (gray symbols in Fig. 2d) yields a relationship that closely follows field-observed changes in phytoplankton absorption with increasing chlorophyll (red line in Fig. 2b). The influence of NPQ likewise emerges by plotting package-corrected, chlorophyll-specific $F_{\text {sat }}\left(\right.$ i.e., $F_{\text {sat }} / C h l_{\text {sat }}$ ) against $i P A R$ (gray symbols in Fig. 2d), with the resultant relationship generally following an inverse function of light (red line in Fig. 2d). By accounting for pigment packaging effects and applying our NPQ correction to $F_{\text {sat }}$ data, a greatly improved relationship (relative to Fig. 2a) is achieved between $F_{\text {sat }}$ and $C h l_{\text {sat }}(r=$ 0.96) (Fig. 2e). Moreover, log-transformation of these quantities reveals a uniform distribution of scatter across the full range of open ocean chlorophyll concentrations (Fig. 2f) that is relatively insensitive to choice of $C h l_{\text {sat }}$ algorithm (Appendix A; Fig. A2). The findings in Fig. 2 illustrate the dominant role of chlorophyll variability, pigment packaging, and NPQ on global $F_{\text {sat }}$ distributions. While the two later phenomena have been the subject of extensive earlier field and laboratory investigations (e.g., Duysens, 1956; Krause and Weis, 1991; Bricaud et al., 1995, 1998; Müller et al., 2001), satellite fluorescence reveals their expression on a scale simply inaccessible at ground level.

\subsection{Nutrient stress and fluorescence yields}

Global NPQ-normalized satellite-based fluorescence quantum yields $\left(\phi_{\text {sat }}\right)$ were calculated using spectrally resolved $a_{p h}^{*}$ (Bricaud et al., 1998; Babin et al., 1996) and an approximation of the spectral shape for downwelling solar irradiance between 400 and $700 \mathrm{~nm}$ (Appendix A). All results reported here are for this spectrally-resolved model (Appendix A, Eq. A8). We also repeated our calculations using a simplified, non-spectral relationship (Appendix A, Eq. A12) that makes the dominant dependencies far easier to visualize:

$$
\begin{aligned}
& \mathrm{NPQ}-\text { corrected } \phi_{\mathrm{sat}}=F_{\mathrm{sat}} \times\left(C h l_{\mathrm{sat}} \times<a_{p h}^{*}>\times S\right)^{-1} \\
& \times i P A R / \overline{i P A R}
\end{aligned}
$$

Equation (3) yields global $\phi_{\text {sat }}$ distributions indistinguishable from those of our full spectral model (Appendix A) and is directly comparable to Eq. (2) but with the additional term, $i P A R / \overline{i P A R}$. This term is the inverse-light correction for NPQ and gives $\phi_{\text {sat }}$ values normalized to the average $i P A R$ for MODIS $\left(\overline{i P A R}=1590 \mu\right.$ mole photons $\left.\mathrm{m}^{-2} \mathrm{~s}^{-1}\right)$. Importantly, $\phi_{\text {sat }}$ values calculated with the spectral (Eq. A8) or simplified (Eq. 3, A12) equations intentionally retain all additional sources of variability in $\phi$ aside from the simple qE-type NPQ response described above because these additional factors are linked to the physiological properties of interest. For example, no attempt is made to correct for other sources of reaction center quenching (qI) (Morrison, 2003; Schallenberg et al., 2008). The influence of these additional factors is reflected in the residual variability remaining in the corrected $F_{\text {sat }}-$ chlorophyll relationship (Fig. 2e and f). For the remainder of this section and in Sect. 3.3, we focus on relationships between our calculated NPQ-corrected $\phi_{\text {sat }}$ distributions and surface nutrient conditions, while additional aspects of $\phi_{\text {sat }}$ variability are discussed in Sect. 4 .

We find a global average value for $\phi_{\text {sat }}$ of $1.0 \%$, which is comparable to high-light quantum yields measured in the field (e.g., Maritorena et al., 2000; Morrison, 2003; Schallenberg et al., 2008). As an initial test of nutrient stress effects, seasonal distributions of $\phi_{\text {sat }}$ (e.g., Fig. 4a) were compared to climatological surface nitrate and phosphate fields (Fig. 4b and c), with no significant correspondence found between elevated $\phi_{\text {sat }}$ and low macronutrient levels. Specifically, only $38 \%$ of the global ocean area with elevated $\phi_{\text {sat }}$ $(>1.4 \%)$ corresponded with low $\mathrm{NO}_{3}$ conditions $(<0.5 \mu \mathrm{M})$ and only $35 \%$ with low $\mathrm{PO}_{4}$ conditions $(<0.25 \mu \mathrm{M})$. However, when $\phi_{\text {sat }}$ is compared to the aeolian deposition of soluble iron (a proxy for iron stress) (Luo et al., 2003; Mahowald et al., 2003; Luo et al., 2008), a clear agreement emerges (Fig. 4a and d). Eighty-two percent of the elevated $\phi_{\text {sat }}$ area is found in regions with low deposition rates $\left(<0.02 \mathrm{ng} \mathrm{m}^{-2} \mathrm{~s}^{-1}\right)$. These regions include the Equatorial Pacific and Southern Ocean and seasonal expanses of the Tropical Indian Ocean and South Pacific (Fig. 4).

Iron stress in phytoplankton has multiple physiological consequences that can contribute to elevated fluorescence emission. First, $\phi$ is defined as the quantum yield for light harvested by all PSI and PSII pigments, not just by the PSII complexes from which fluorescence emanates. This practical definition reflects the fact that PSII and PSI pigment concentrations are not distinguished in the field (or from space) and it imparts a direct link between $\phi$ and physiological adjustments in PSII:PSI stoichiometry. Importantly, iron stress is a key environmental factor influencing PSII:PSI ratios in natural phytoplankton populations. Under low iron conditions, phytoplankton increase PSII:PSI by a factor of 2.5 to 4.0 (Sandmann, 1985; Vassiliev et al. 1995, Ivanov et al., 2000; Strzepek and Harrison, 2004). This response has been suggested as an adaptive strategy in phytoplankton for balancing ATP supplies with demand (Behrenfeld et al., 2008). The consequence of a PSII:PSI increase, assuming no compensating phenomena, is a proportional upward shift in pigment-specific fluorescence yields (Fig. 3c), thus contributing to elevated values of $\phi_{\text {sat }}$ (Fig. 4a and d).

"Whole curve" shifts in $\phi$-iPAR relationships similar to those shown in Fig. $3 \mathrm{c}$ are also associated with PSII inactivation (qI). Morrison (2003) and Schallenberg et al. (2008) illustrate such changes for a range of qI values. At the incident 

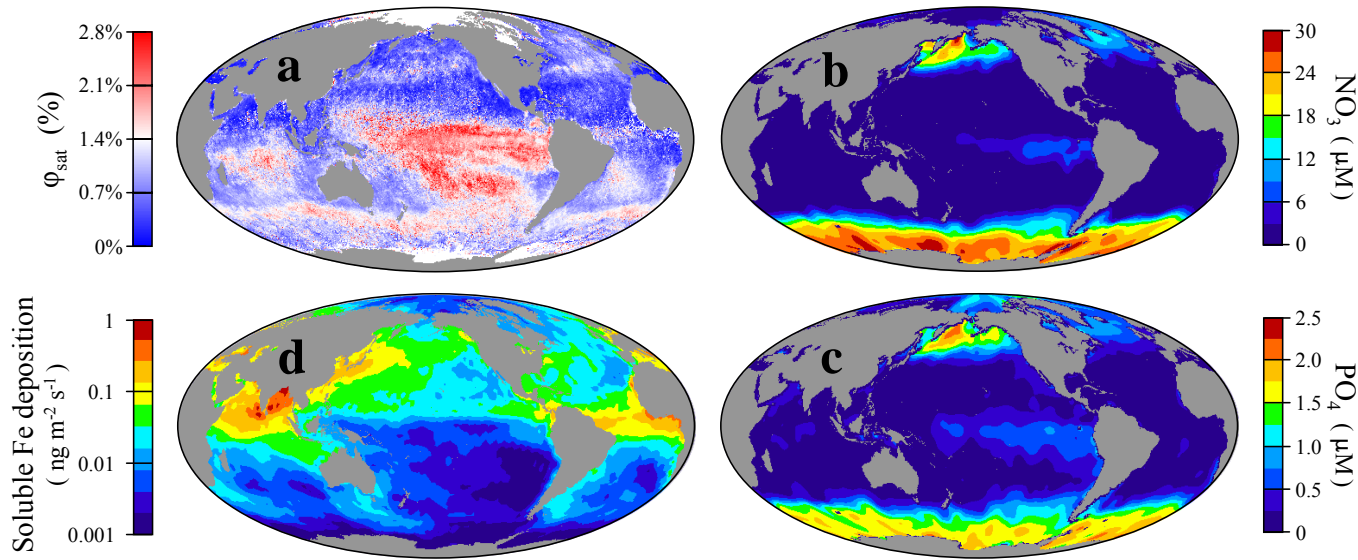

Fig. 4. Comparison of (a) $\phi_{\text {sat }}$ with (b) surface nitrate concentration, (c) surface phosphate concentration, and (d) aeolian soluble iron deposition. Values of $\phi_{\text {sat }}$ and iron deposition are for spring 2004 (March-May). $\mathrm{NO}_{3}$ and $\mathrm{PO}_{4}$ are World Ocean Atlas climatological spring values. White pixels in (a) indicate ice cover.

light levels of MODIS observations, phytoplankton can reversibly down-regulate a significant fraction of PSII centers. This light-driven form of qI protects active reaction centers from photodamage while maintaining overall photosynthetic electron flow (Behrenfeld et al., 1998) and is significantly influenced by iron stress. Specifically, light-driven downregulation of PSII can result once light absorption is sufficient to saturate (i.e., reduce) the plastoquinone (PQ) pool (Kok, 1956; Kyle, 1987; Barber, 1991, 1992; Prasil et al., 1992; Osmond, 1994; Behrenfeld et al., 1998). These deactivated centers suppress the $\phi$-iPAR relationship by dissipating core photon energy as heat (Krause and Jahns, 2004). However, susceptibility to PSII damage can be significantly reduced by rapid electron transport from PSII to oxygen through PQ pool mid-stream oxidases (e.g., PTOX) (Bailey and Grossman, 2008; Bailey et al., 2008; Cardol et al., 2008; Mackey et al., 2008). These mid-stream oxidases have been implicated as a key pathway for ATP generation under iron stress (Behrenfeld et al., 2008) and are likely involved in the observed lower susceptibility of natural iron stressed phytoplankton populations to photoinhibition relative to iron replete communities (Behrenfeld and Kolber, 1999; their Fig. 3a). The associated reduction in qI under iron stress would thus contribute to elevated values of $\phi_{\text {sat }}$ (Fig. 4a and d).

Finally, iron stress in the presence of elevated macronutrients (i.e., HNLC conditions) leads to an over-expression of pigment-protein complexes relative to reaction center density (Behrenfeld et al., 2006b). The presence of these "disassociated" antennae complexes generally enhances fluorescence emission in HNLC phytoplankton and may additionally contribute to elevated $\phi_{\text {sat }}$ values (Fig. $4 \mathrm{a}$ and d). The observation that these complexes are expressed under low iron, high macronutrient conditions but not low iron, low macronutri- ent conditions (Behrenfeld et al., 2006b) suggests a regulatory role for macronutrients in signaling synthetic pathways for light harvesting components.

Physiological impacts on photosystem stoichiometry, qI, and pigment-protein composition provide a mechanistic link between iron stress and enhanced satellite fluorescence yields. However, this relationship may not be fully captured in comparisons of high $\phi_{\text {sat }}$ and low iron deposition (Fig. $4 \mathrm{a}$ and d) because aeolian deposition alone is not the only factor controlling iron stress in the open ocean. Additional important factors include upwelling of iron from depth, ecosystem recycling, and biomass-dependent competition for available iron. Likewise, macronutrient stress is not fully represented by surface concentrations because of similar ecosystem processes. To further investigate the link between nutrient stress and $\phi_{\text {sat }}$, we therefore employed coupled ocean circulationecosystem models with active iron cycling.

\subsection{Satellite fluorescence yields and nutrient stress in biogeochemical models}

Ocean circulation-ecosystem models quantify biotic and abiotic nutrient fluxes and pools in the upper ocean and provide climatological predictions of growth constraints on an appropriate scale for comparison with satellite $\phi_{\text {sat }}$ distributions (Fig. 5). From these models, the relative bio-availability of macro- and micro-nutrients can be evaluated and an assessment made of the most limiting environmental factor for phytoplankton growth. For our global analysis, we constructed from model results (Moore et al., 2006; Moore and Braucher, 2008) a "Growth Constraint Index" (GCI) distinguishing iron limited waters (blue areas in Fig. 5b and e) from regions limited by macronutrients $(\mathrm{N}, \mathrm{P})$ or light (red areas in Fig. 5b and e). Resultant GCI distributions reveal a clear correspondence between elevated $\phi_{\text {sat }}(>1.4 \%)$ and 

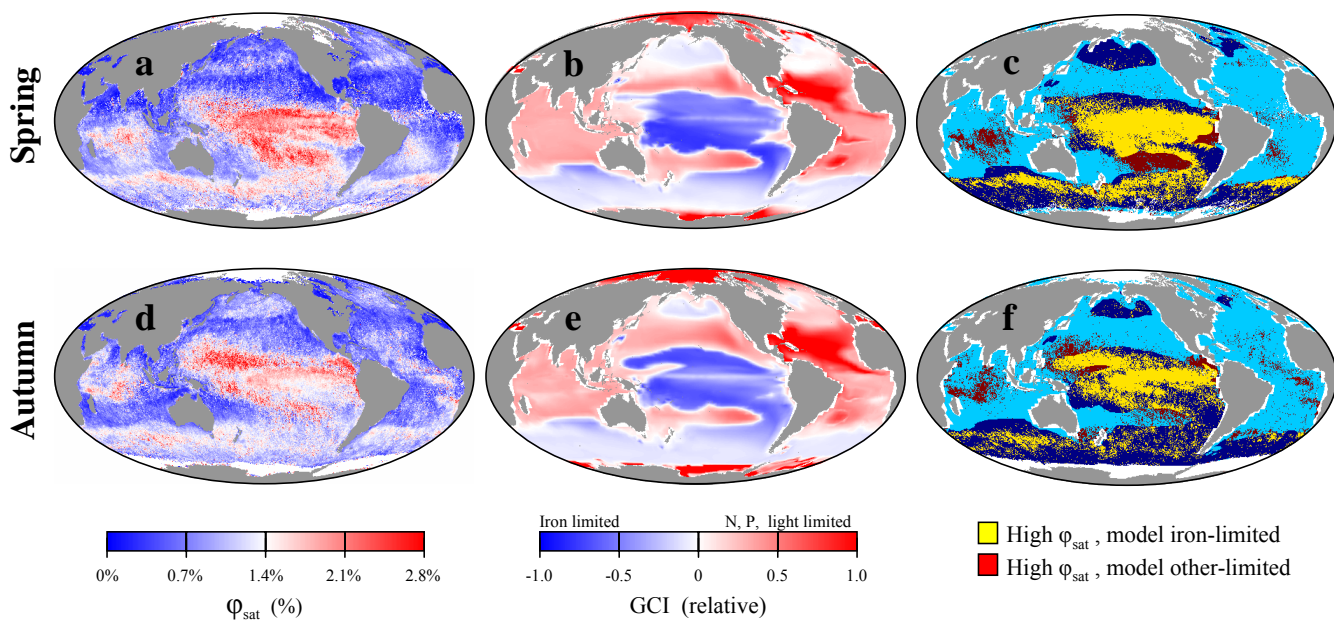

Fig. 5. Comparison of global $\phi_{\text {sat }}$ and model-based GCI (Moore et al., 2006) for (a-c) boreal spring (March-May) and (d-f) boreal autumn (September-November). (a, d) $=\phi_{\text {sat }} .(\mathbf{b}, \mathbf{e})=$ GCI. The model generates a relative stress index (0 to 1) for each growth factor (iron, light, $\mathrm{N}, \mathrm{P})$. GCI is the log transform of the ratio of the iron stress index to that for the most limiting other factor (light, $\mathrm{N}$, or $\mathrm{P})$. Blue $=\mathrm{GCI}<0$, Fe limited. Red = GCI $>0$, macronutrient or light-limited. (c, f) State-space comparison of satellite and model results. (background) Dark blue $=\mathrm{GCI}<0$. Light blue $=\mathrm{GCI}>0$ (foreground). Yellow $=$ high $\phi_{\text {sat }}(>1.4 \%)$ matches model iron stress. Red $=$ high $\phi_{\text {sat }}$ coincides with other model stress. Spring and autumn seasons are shown because the latitudinal distribution of light is most evenly distributed across midand low-latitudes during these periods, thus minimizing impacts of physiological light acclimation (see Fig. 3d).

model predicted locations of iron stress (yellow pixels in Fig. $5 \mathrm{c}$ and $\mathrm{f}$ ), with most mismatches occurring in the Indian Ocean and along GCI boundaries (red pixels in Fig. 5c and f). Likewise, model predicted macronutrient- or lightlimited waters are typically associated with low $\phi_{\text {sat }}$ values, such as across the Atlantic where the GCI indicates a general absence of iron stress. For the boreal spring and autumn seasons shown in Fig. 5, 70\% of the global ocean area exhibiting elevated $\phi_{\text {sat }}(>1.4 \%)$ corresponds to model predicted regions of iron stress, while $86 \%$ of the ocean area predicted to be macronutrient- or light-limited exhibits low $\phi_{\text {sat }}(<1.4 \%)$. This agreement of satellite observations and model predictions is rather remarkable given the spatial (satellite $=9 \mathrm{~km}$ at equator; model $=3.6^{\circ}$ longitudinal, $>1^{\circ}$ latitudinal) and temporal $($ satellite $=$ single season $;$ model $=$ climatology $)$ in consistencies between these data sources.

The global $\phi_{\text {sat }}$ - model comparison presented in Fig. 5 supports iron stress as an important physiological factor regulating fluorescence yields. In the Indian Ocean, however, the global model predicts that phytoplankton growth is uniformly limited by macronutrients, while elevated $\phi_{\text {sat }}$ values in the region imply an occurrence of iron stress. High $\phi_{\text {sat }}$ values in the Indian Ocean are particularly prominent during summer, extending nearly the full width of the southtropical basin and continuing northward along the Somali coast (Fig. 6a). To investigate this feature further, GCI distributions were reconstructed for the Indian Ocean using a higher-resolution coupled model developed specifically for the region (Wiggert et al., 2006, 2007) that better cap- tures seasonal upwelling processes. This model predicts that macronutrients $(\mathrm{N})$ limit surface phytoplankton growth during summer in the Northern Indian Ocean outside of prominent upwelling areas (red areas in Fig. 6b), while iron emerges as the most limiting nutrient in south-tropical and western regions (blue areas in Fig. 6b) (Wiggert et al., 2006, 2007). Comparison of these satellite (Fig. 6a) and model results (Fig. 6b) reveals a strong correspondence (Fig. 6c), with $82 \%$ of elevated $\phi_{\text {sat }}$ values $(>1.4 \%)$ corresponding to model predicted iron stress regions and $85 \%$ of low $\phi_{\text {sat }}$ values $(<1.4 \%)$ corresponding to model predicted areas of $\mathrm{N}$ limitation. Significant correlations are likewise found during boreal autumn and winter, but not during spring when the model predicts iron stress to be relatively weak across the basin (Wiggert et al., 2006). Recognizing again the spatial and temporal inconsistencies between these data sources, the overall agreement between satellite and model results is encouraging. If the strong iron stress feature illustrated in Fig. 6 is upheld by future field studies, satellite fluorescence measurements will have provided the first synoptic observational evidence that iron plays an important role in the seasonal phytoplankton dynamics of this broad, yet sparsely sampled, ocean region. ${ }^{11}$

\footnotetext{
${ }^{11}$ Recent results from field bottle-enrichment experiments evidence an occurrence of iron stress in coastally upwelled waters of the Arabian Sea during the SW Monsoon (Moffett, J. W.; Naqvi, S. W. A.; Gaum, M. and Valavala, D., 2008, Ocean Sciences Meeting Abstract, Orlando, Florida, USA).
} 


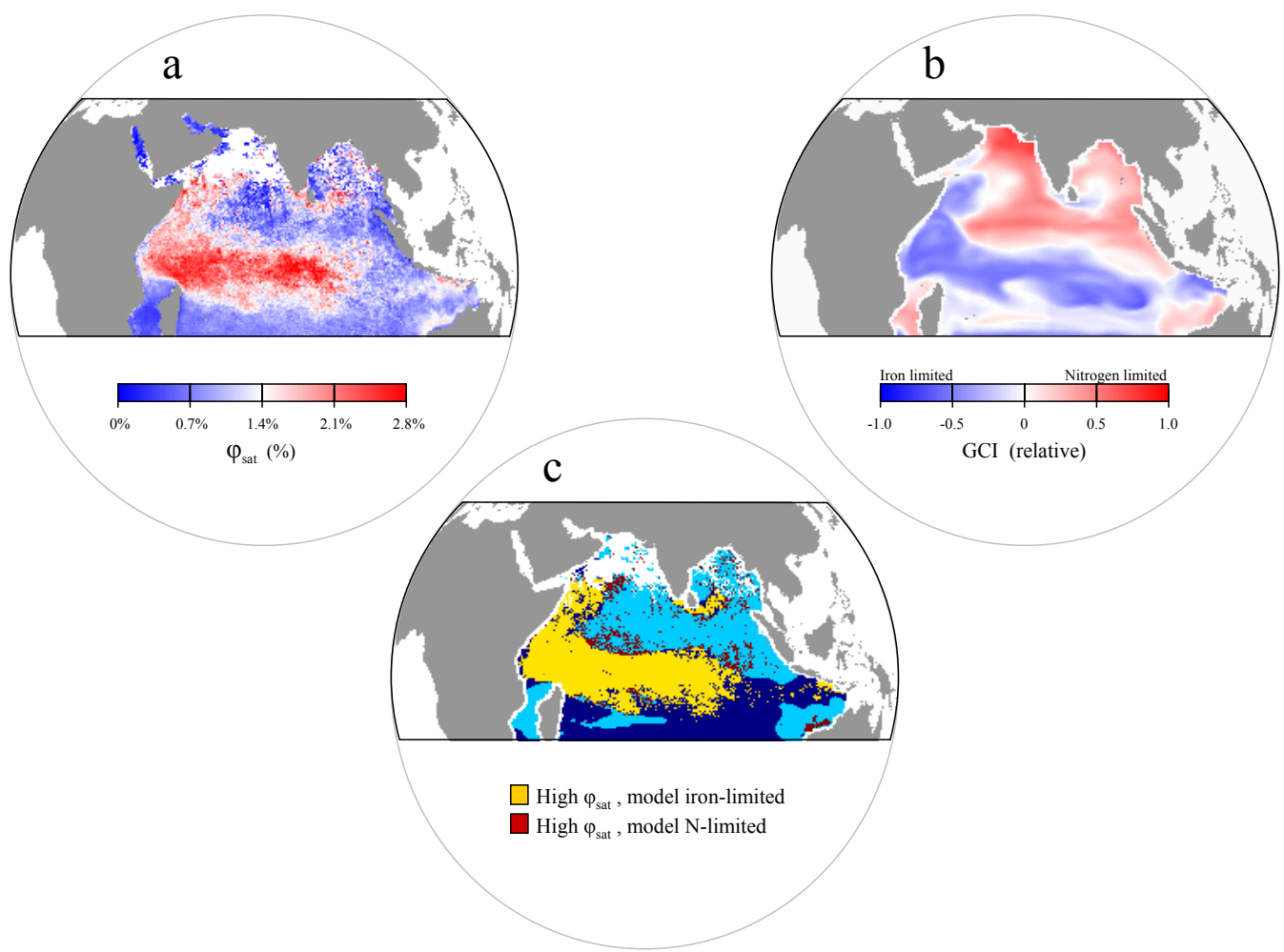

Fig. 6. Indian Ocean (a) $\phi_{\text {sat }}$ and (b) model-based GCI (Wiggert et al., 2006) for boreal summer (June-August). (b) Blue = Fe limited. Red $=$ Nitrogen limited. (c) State-space comparison of $\phi_{\text {sat }}$ and GCI (colors as in Fig. $5 \mathrm{c}$ and f).

\section{The satellite fluorescence era: conclusions and future directions}

Climate variability strongly impacts ocean phytoplankton productivity through its influence on the surface-layer light environment, subsurface nutrient supplies, and the aeolian flux of iron-laden dust (Behrenfeld et al. 2001; Gregg et al., 2005; Behrenfeld et al., 2006a; Schneider et al., 2008). These climate-driven changes in ocean biology can be equally expressed as changes in phytoplankton biomass or physiology (Behrenfeld et al., 2008), but global-scale physiological changes elude traditional field or remote sensing approaches. Indeed, even surface nutrient inventories (e.g., Fig. 4b and c) require decades of field measurements to assemble, obfuscating climate-biology interactions functioning on shorter time-scales (e.g., El niño - La niña fluctuations). Phytoplankton chlorophyll fluorescence is a remotely retrievable property registering a variety of physiological characteristics, with a long history of research and application (e.g., Neville and Gower, 1977; Morel and Prieur, 1977; Topliss and Platt, 1986; Kiefer et al., 1989; Babin et al., 1996; Letelier et al., 1997; Abbott and Letelier, 1999; Maritorena et al., 2000; Morrison, 2003; Gower et al., 2004; Laney et al., 2005; Huot et al., 2007, and other citations herein). Building from this foundation, we here extend the analysis of fluo- rescence as a physiological indicator to the global scale and document the broad expression of key factors influencing fluorescence yields and linked to climate-sensitive upper-ocean growth conditions.

Iron supply to the open ocean is increasingly recognized as one of the crucial links between climate and ocean biology, functioning on short- to geologic time scales (Martin, 1990; Martin et al., 1991). Evidence of iron's important role has expanded from simple bottle experiments (e.g., Martin and Fitzwater, 1988; Martin et al., 1991, 1994; Fitzwater et al., 1996), to kilometer-scale in situ enrichments (e.g., Martin et al., 1994; Coale et al., 1996; Boyd et al., 2000; Tsuda et al., 2003; Boyd et al., 2007), to basin-scale diagnostic studies (Behrenfeld and Kolber, 1999; Behrenfeld et al., 2006b), and potentially now to continuous globalscale assessments through satellite fluorescence. Correspondences reported here between elevated $\phi_{\text {sat }}$ values, low aeolian iron deposition, and model predictions of iron limitation provide compelling evidence for this new iron stress detection capability. As an iron stress index, $\phi_{\text {sat }}$ distributions offer a unique opportunity to evaluate model predictions of nutrient limitation (e.g., Figs. 5, 6), uncover new ocean regions of iron stress (Fig. 6), and improve ocean productivity estimates through the separate parameterization of light use efficiencies for iron-limited versus non-iron-limited 
populations (e.g., Behrenfeld et al., 2006b). Observations of $\phi_{\text {sat }}$ may also provide a new tool for detecting phytoplankton responses to natural iron deposition events or other perturbations to surface layer iron budgets.

Although results presented here represent a forward step in the long-standing quest to globally characterize physiological constraints on phytoplankton growth, additional advances await further investigations of fluorescence variability. For example, while we find that elevated $\phi_{\text {sat }}$ values are associated with low iron conditions and that regions of macronutrient limitation are typically associated with low $\phi_{\text {sat }}$ values, we do not find that all predicted iron limited waters have high $\phi_{\text {sat. }}$. These discrepancies are identified in Fig. 5c and $\mathrm{f}$ by dark blue pixels. In some cases, these mismatches represent errors in nutrient stress predictions of the model, particularly in waters where both macronutrients and iron are at the threshold of limitation. In other cases, however, low $\phi_{\text {sat }}$ values are found in waters well established as iron limited, such as the subarctic north Pacific and highest latitudes of the Southern Ocean (Fig. 5) (Boyd et al., 2007). Such occurrences can be attributed to additional physiological factors influencing fluorescence yields.

In the current treatment, a simple inverse-light function is used to describe qE-type NPQ. While such a relationship may be appropriate for phytoplankton acclimated to a single light level (Figs. 2c, 3a and b) and is consistent to firstorder with our satellite data (Fig. 2c), the actual reduction in $\phi_{\text {sat }}$ from NPQ expressed at any given saturating $i P A R$ differs between phytoplankton acclimated to different light levels (Fig. 3d). Specifically, phytoplankton acclimated to a variable light environment with a low median light level must dissipate a greater fraction of absorbed light energy as heat when exposed to high-irradiance than phytoplankton acclimated to a variable light environment with a higher median light level but similar maximum irradiance. This relationship between NPQ and light acclimation state is illustrated in Fig. 3d. Importantly, the mixed layer light levels to which phytoplankton photoacclimate are typically lower at high latitudes than nearer the equator. Applying a single inverselight function at all latitudes, therefore, will tend to overcorrect for NPQ at high latitudes, yielding dampened $\phi_{\text {sat }}$ values. This consideration alone may account for the general absence of elevated $\phi_{\text {sat }}$ in the high-latitude, iron limited waters of the subarctic Pacific and southern Ocean (Fig. 5). Addressing this issue represents an important challenge for future satellite fluorescence analyses and will require the description of NPQ as a function of both $i P A R$ and photoacclimation state, where the latter term should be considered from the perspective of the mixed layer light environment and its fluctuations on physiologically-relevant time scales.

In addition to photoacclimation-dependent variability in the $\phi-i P A R$ relationship (Fig. 3d), other factors can be included in future analyses of global $\phi_{\text {sat }}$ distributions. For example, we have discussed the contribution of reversible PSII down-regulation to qI, but have not addressed other factors influencing qI. In particular, laboratory and field results indicate that balanced growth under steady state nutrient stress is not associated with an increase in qI (e.g., Parkhill et al., 2001; Behrenfeld et al., 2006b; Kruskopf and Flynn, 2006; Halsey et al., 2009), but significant inactivation of PSII centers can be observed during the onset of nutrient starvation (e.g., Thomas and Dodson, 1972; Young and Beardall, 2003) and qI-type NPQ not associated with the diurnal light cycle has been observed in the field (e.g., Schallenberg et al., 2008). Future $\phi_{\text {sat }}$ analyses may also consider taxonomic factors, particularly with respect to their influence on $\phi_{\text {sat }}$ through changes in accessory pigments or PSII:PSI responses to iron stress. As these remaining issues are resolved, we can anticipate new insights on phytoplankton physiology and ecology to emerge from the satellite chlorophyll fluorescence record, as well as an independent global data set for regionally- and globally evaluating satellite chlorophyll retrieval algorithms (e.g., Fig. A2).

\section{Appendix A}

\section{A1 Derivation of fluorescence quantum yield from space}

In the following subsections, we describe the stepwise treatment of the fluorescence signal as measured with NASA's MODIS sensor on Aqua that culminates in a phytoplankton fluorescence quantum yield accounting for effects of pigment packaging and non-photochemical quenching. For all calculations, we use satellite surface chlorophyll estimates $\left(C h l_{\text {sat }}\right)$ from the OC-3 standard NASA algorithm and MODIS $i P A R$ data based on Carder et al. (2003).

\section{A2 Satellite ocean color measurement of chlorophyll fluorescence}

Satellite measurements of chlorophyll fluorescence from the MODIS sensor, $F_{\text {sat }}$, are derived from determinations of the normalized water leaving radiance, $L_{W N}(\lambda)$ (e.g., Abbott and Letelier, 1999). Values of $L_{W N}(\lambda)$ (a level 2 data product from NASA's processing stream; http://oceancolor.gsfc. nasa.gov/PRODUCTS) are related to the water leaving radiance $\left(L_{W}(\lambda)\right)$ through:

$L_{W N}(\lambda)=L_{W}(\lambda) \frac{F_{0}(\lambda)}{E_{d}\left(0^{+}, \lambda\right)}$

where $E_{d}\left(0^{+}, \lambda\right)$ is downwelling irradiance just above the sea surface and $F_{0}(\lambda)$ is the solar irradiance spectrum at the top of the atmosphere (Gordon and Voss, 1999). Three processes contribute to water leaving radiance near the peak of chlorophyll fluorescence emission, $L_{W}$ (678): elastic backscattering of light, Raman scattering by water, and chlorophyll fluorescence (e.g., Kiefer et al., 1989; Westberry and Siegel, 2003). To obtain the chlorophyll fluorescence signal from 


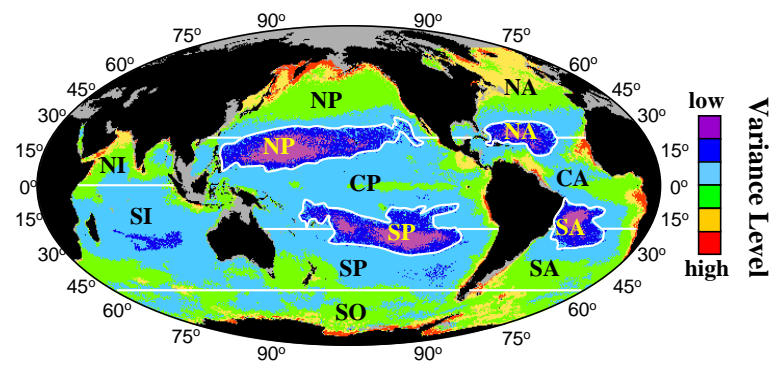

Fig. A1. For Fig. 2 of the manuscript, monthly $F_{\text {sat }}$ data for the 5-year MODIS record were separated into 34 regional bins. Bin designations were based on annual variance in satellite chlorophyll concentration $\left(C h l_{\text {sat }}\right)$ as described in Behrenfeld et al. (2005). The only difference between the current bin set and the earlier study of Behrenfeld et al. (2005) is that the Southern Ocean is now also divided into variance bins, rather than treating the entire region as a single bin. The 34 bins are distinguished here by ocean basin and color. NP, CP, SP = North, Central, and South Pacific. NA, CA, SA $=$ North, Central, and South Atlantic. NI, SI = North and South Indian. $\mathrm{SO}=$ Southern Ocean. Colors indicate $C h l_{\text {sat }}$ variability from lowest (purple) to highest (red). Gray indicates excluded areas.

ocean color remote sensing, a line height calculation is performed that approximately removes effects of backscattering and Raman scattering (Abbott and Letelier, 1999):

$F_{\text {sat }}=L_{W N}(678)-\frac{70}{81} L_{W N}(667)-\frac{11}{81} L_{W N}(748)$,

where $L_{W N}(\lambda)$ are the water leaving radiances at the respective wavelengths in units of $\mathrm{mW} \mathrm{cm}^{-2} \mathrm{sr}^{-1} \mu \mathrm{m}^{-1}$. $F_{\text {sat }}$ is currently a MODIS level-3 evaluation product (http://oceancolor.gsfc.nasa.gov/cgi/13). Fluoresced radiance $L_{W, f}\left(0^{+}, 678\right)$, also called fluorescence line height, is equal to:

$L_{W, f}\left(0^{+}, 678\right)=F_{\mathrm{sat}} \frac{E_{d}\left(0^{+}, 678\right)}{F_{0}(678)}$,

where $F_{0}(678)$ is $148.097 \mathrm{~mW} \mathrm{~cm}^{-2} \mu \mathrm{m}^{-1}$ (Thuillier et al., 2003).

\section{A3 Fluorescence radiance emanating from the oceans}

The contribution of fluoresced radiance from a subsurface layer between $\mathrm{z}_{1}$ and $\mathrm{z}_{1}+\Delta \mathrm{z}$ and measured at the emission band $\left(\lambda_{e m}\right)$ is:

$$
\begin{aligned}
& \Delta L_{W, f}\left(z_{1}, \Delta z, \lambda_{e m}\right)=\frac{\varphi}{4 \pi C_{f}} \int_{z 1+\Delta z}^{z 1} \int_{400 \mathrm{~nm}}^{700 \mathrm{~nm}} \frac{\lambda}{h c} \\
& a_{p h}(z, \lambda) E_{0}\left(0^{-}, \lambda\right) e^{-K(\lambda, z) z} d \lambda d z
\end{aligned}
$$

where the integral with respect to depth accounts for the loss of light energy with depth at a rate equal to the diffuse attenuation coefficient $K(\mathrm{z}, \lambda)\left(\mathrm{m}^{-1}\right)$ and absorbed by phytoplankton with an absorption coefficient $a_{p h}(\mathrm{z}, \lambda)\left(\mathrm{m}^{-1}\right)$. In Eq. (A4), the $4 \pi$ factor accounts for the fact that fluorescence is isotropic, $C_{f}(\mathrm{~nm})$ is the inverse proportion of photons fluoresced at the detected emission waveband around $\lambda_{e m}$ relative to the full fluorescence spectrum, $\phi$ is the quantum yield of fluorescence (total number of fluoresced photons per absorbed photons), $E_{0}\left(0^{-}, \lambda\right)$ is the scalar irradiance $\left(\mathrm{W} \mathrm{m}^{-2} \mathrm{~nm}^{-1}\right)$, and the factor, $\lambda / h c$, translates $E_{0}\left(0^{-}, \lambda\right)$ into units of quanta $\mathrm{m}^{-2} \mathrm{~s}^{-1} \mathrm{~nm}^{-1}$ (e.g., Kiefer et al., 1989; Huot et al., 2005). The units of $\Delta L_{W, f}\left(z_{1}, \lambda_{e m}\right)$ are thus quanta $\mathrm{m}^{-2} \mathrm{~s}^{-1} \mathrm{~nm}^{-1} \mathrm{sr}^{-1}$.

We next assume an optically homogeneous upper ocean in terms of the phytoplankton absorption coefficient and diffuse attenuation coefficients. This assumption introduces little error because remotely detected fluorescence originates from the upper few meters of the ocean and is measured with the sun near its highest position in the sky. We also neglect reabsorption of fluoresced light within the emitting phytoplankton (e.g., Collins et al., 1985), which is valid for $C h l<2 \mathrm{mg} \mathrm{m}^{-3}$ (Fig. 1 in Huot et al., 2005).

Fluoresced light is attenuated on its way to the surface with a diffuse attenuation coefficient, $k_{L}\left(\lambda_{e m}\right)$. Integrating over all depths $z$ contributing to fluoresced light (e.g. Keifer et al., 1989; Huot et al., 2005), we get:

$L_{W, f}\left(0^{-}, \lambda_{e m}\right)=\frac{\varphi}{4 \pi C_{f}} \int_{400}^{700} \frac{\lambda}{h c} \frac{1}{\left(K(\lambda)+k_{L}\left(\lambda_{e m}\right)\right)}$
$a_{p h}(\lambda) E_{0}\left(0^{-}, \lambda\right) d \lambda$

The fluoresced water-leaving radiance, $L_{w, f}\left(0^{+}, \lambda_{e m}\right)$, is equal to the fluoresced radiance just beneath the sea surface, $L_{w, f}\left(0^{+}, \lambda_{e m}\right)$, transmitted across the air-sea interface:

$L_{W, f}\left(0^{+}, \lambda_{e m}\right)=\frac{t L_{W, f}\left(0^{-}, \lambda_{e m}\right)}{n_{w}^{2}}=0.54 L_{W, f}\left(0^{-}, \lambda_{e m}\right)$,

where $n_{w}$ is the index of refraction of sea water $\left(n_{w}=1.34\right)$ and $t$ is transmission of nadir radiance across the sea surface $(t=0.97$; Mobley, 1994).

\section{A4 Quantum yield determination}

Combining (A5) and (A6), equating it with (A3) at the emission wavelength $(678 \mathrm{~nm})$, and solving for the quantum yield, we get:

$\varphi_{\mathrm{sat}}=\frac{4 \pi n_{w}^{2} C_{f}}{t F_{0}(678)} \frac{E_{d}\left(0^{+}, 678\right) F_{\mathrm{sat}}}{\int_{400}^{700} \frac{\lambda}{h c} \frac{1}{K(\lambda)+k_{L}(678)} a_{p h}(\lambda) E_{0}\left(0^{-}, \lambda\right) d \lambda}$.

where $C_{f}=43.38 \mathrm{~nm}$ for MODIS (Huot et al., 2005). For calculating $\phi_{\text {sat }}$, incident irradiance, $E_{d}\left(0^{+}, \lambda\right)$, was reconstructed from $I P A R$ using a representative spectral shape 

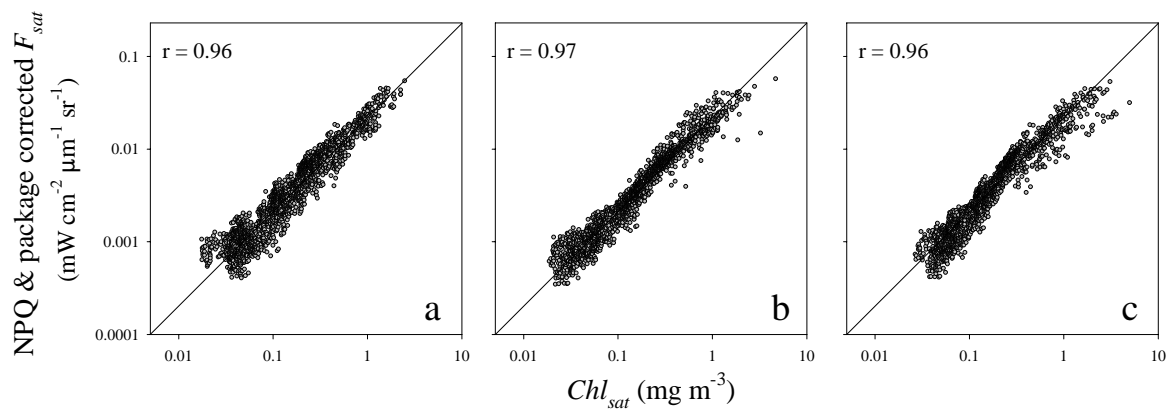

Fig. A2. Comparison of binned monthly $F_{\text {sat }}$ data (corrected for NPQ and package effects) and satellite chlorophyll (Chl $\left.l_{\text {sat }}\right)$ for three different chlorophyll algorithms. (A) MODIS standard empirical OC-3 algorithm. (B) Quasi-Analytical Algorithm (Lee et al., 2002). (C) Garver-Siegel-Maritorena semi-analytical algorithm (Maritorena et al., 2002). Correlation coefficients ( $r$ ) for log-transformed data are shown in each panel. Panel (A) is identical to Fig. 2F in the main manuscript.

for the subtropics under typical sky conditions (Gregg and Carder, 1990). Variability due to changes in solar zenith angle, cloudiness, and atmospheric composition were found to be small ( $<6 \%$, e.g. Westberry et al., 2008). Diffuse transmittance across the air-sea interface was assumed constant $(t=0.97$, Mobley, 1994) and spectral scalar irradiance, $E_{o}(\lambda)$, was estimated as $E_{o}(\lambda)=E_{d}(\lambda) / 0.87$, where the factor 0.87 is an "average" conversion between scalar and planar irradiance based on radiative transfer simulations (Westberry and Siegel, 2003; Morel and Gentilli, 2004). Total light attenuation is the dominant attenuation of the fluoresced upwelling light by water $\left(k_{L}(678) \sim a_{w}(678)=0.46 \mathrm{~m}^{-1}\right)$ plus the weaker attenuation of downwelling light (valid for $C h l<2 \mathrm{mg} \mathrm{m}^{-3}$, Kiefer et al., 1989), giving the approximation: $K(\lambda)+k_{L}(678)=0.52 \mathrm{~m}^{-1}$. Finally, a correction for qE-type NPQ was applied using an inverse light function normalized to the average $i P A R$ value for the MODIS record $\left(\overline{i P A R}=1590 \mu\right.$ mole photons $\left.\mathrm{m}^{-2} \mathrm{~s}^{-1}\right)$ (i.e., NPQ correction $=i P A R / \overline{i P A R})$. Thus,

$$
\begin{aligned}
& \mathrm{NPQ}-\text { corrected } \varphi_{\text {sat }}=\frac{6.8 E_{d}\left(0^{+}, 678\right) F_{\text {sat }}}{\int_{400}^{700} \frac{\lambda}{h c} \frac{1}{0.52} a_{p h}(\lambda) \frac{0.97 E_{d}\left(0^{+}, \lambda\right)}{0.87} d \lambda} \frac{i P A R}{1590} \\
& =0.002 \frac{E_{d}\left(0^{+}, 678\right) F_{\text {sat }} i P A R}{\int_{4000}^{700} a_{p h}(\lambda) E_{d}\left(0^{+}, \lambda\right) d \lambda} .
\end{aligned}
$$

NPQ-corrected $\phi_{\text {sat }}$ data presented in the main manuscript were calculated with equation (A9), where $a_{p h}(\lambda)$ was calculated from of Bricaud et al. (1998):

$a_{p h}(\lambda)=A_{p}(\lambda) C h l^{E p(\lambda)}$

using $A_{p}(\lambda)$ and $E_{p}(\lambda)$ values specified at $2 \mathrm{~nm}$ intervals between $400-700 \mathrm{~nm}$. However, by employing two additional approximations, a surprisingly compact expression for the quantum yield emerges. First, the incident solar spectrum can be taken to be spectrally flat such that:

$E_{d}\left(0^{+}, \lambda\right)=\frac{\int_{400}^{700} E_{d}\left(0^{+}, \lambda\right) d \lambda}{300 \mathrm{~nm}}=0.0033$ iP PR.
Second, an average spectrally-weighted phytoplankton absorption coefficient $\left.\left(<a_{p h}\right\rangle\right)$ can be estimated from the model of Bricaud et al. (1998). Specifically, we calculated $<a_{p h}>$ as a function of $C h l_{\text {sat }}$ using $a_{p h}(\lambda)$ values and then fit the resultant relationship using a power-law function, similar to Babin et al. (1996):

$<a_{p h}>=C h l_{\text {sat }}<a_{p h}^{*}>=0.0147 C h l_{\text {sat }}^{0.684}$,

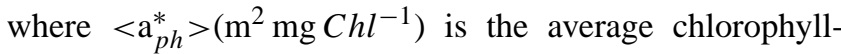
specific absorption coefficient. Combining equations (A8), (A10) with (A11), we get the simplified expression for NPQcorrected $\phi_{\text {sat }}$ of:

$$
\begin{aligned}
& \mathrm{NPQ}-\text { corrected } \varphi_{\mathrm{sat}}=0.00043 \frac{F_{\mathrm{sat}} i P A R}{C h l_{\mathrm{sat}}^{0.684}} \\
& =0.01 \frac{F_{\mathrm{sat}}}{C h l_{\mathrm{sat}}<a_{p h}^{*}>} \frac{i P A R}{\overline{i P A R}} .
\end{aligned}
$$

Equation (A12) relates NPQ-corrected $\phi_{\text {sat }}$ to three satellite-derived products $\left(F_{\text {sat }}, i P A R, C h l_{\text {sat }}\right)$ and has the basic form of Eq. (3) in the main manuscript, where the constant 0.01 is the inverse of $S$. NPQ-corrected $\phi_{\text {sat }}$ values from Eq. (A12) have global distributions that are indistinguishable from those from Eq. (A8), but are on average 19\% lower. This offset between the two data sets is due to the flat spectrum described in Eq. (A10) overestimating total absorbed radiation relative to the spectrally resolved description in Eq. (A8). Adding a 19\% correction to Eq. (A12) gives global NPQ-corrected $\phi_{\text {sat }}$ values that are within $\pm 1.6 \%$ (standard deviation) of those from Eq. (A8).

As a final note, the focus of the current manuscript is on the characterization of phytoplankton physiological variability, but this is not the only valuable application of satellite fluorescence data. As illustrated in Fig. 2e and f, global variability in fluorescence quantum yields is highly constrained relative to variability in chlorophyll concentration (e.g., Fig. 1b). 
Accordingly, correction of fluorescence data for primary factors contributing to quantum yield variations (e.g., Eq. A12) yields products that could be used to evaluate regional biases in satellite chlorophyll products from the alternative empirical- and semi-analytic algorithms based on measurement bands in the blue-green spectral region (e.g., Fig. A2).

\section{Appendix B}

Table B1. Notation.

\begin{tabular}{|c|c|}
\hline$<a_{p h}^{*}>$ & $\begin{array}{l}\text { Spectrally averaged chlorophyll specific absorption coefficient } \\
{\left[\mathrm{m}^{2}(\mathrm{mg} \mathrm{chl} \mathrm{a})^{-1}\right]}\end{array}$ \\
\hline$<\overline{a_{p h}^{*}}>$ & $\begin{array}{l}\text { Spectrally averaged chlorophyll specific absorption coefficient } \\
\text { for the global average surface chlorophyll concentration of } \\
0.134 \mathrm{mg} \mathrm{m}^{-3}\left[\mathrm{~m}^{2}(\mathrm{mg} \mathrm{chl} \mathrm{a})^{-1}\right]\end{array}$ \\
\hline$a_{p h}^{*}(\lambda)$ & $\begin{array}{l}\text { Chlorophyll specific absorption coefficient at wavelength, } \\
\lambda\left[\mathrm{m}^{2}(\mathrm{mg} \mathrm{chl} \mathrm{a})^{-1}\right]\end{array}$ \\
\hline$C h l_{\text {sat }}$ & Satellite-derived surface chlorophyll concentration $\left[\mathrm{mg} \mathrm{m}^{-3}\right]$ \\
\hline$F$ & $\begin{array}{l}\text { Chlorophyll fluorescence } \\
{\left[\mathrm{mW} \mathrm{cm} \mathrm{cm}^{-2} \mu \mathrm{m}^{-1} \mathrm{sr}^{-1}\right]}\end{array}$ \\
\hline$F_{\mathrm{sat}}$ & $\begin{array}{l}\text { Satellite-derived surface chlorophyll fluorescence } \\
{\left[\mathrm{mW} \mathrm{cm}{ }^{-2} \mu \mathrm{m}^{-1} \mathrm{sr}^{-1}\right]}\end{array}$ \\
\hline iPAR & $\begin{array}{l}\text { Incident solar irradiance integrated over the } 400 \text { to } 700 \mathrm{~nm} \\
\text { waveband }\left[\mu \text { mole photons } \mathrm{m}^{-2} \mathrm{~s}^{-1} \text { ] }\right. \\
i P A R \\
\text { Average } i P A R \text { for MODIS observations }= \\
1590 \mu \text { mole photons } \mathrm{m}^{-2} \mathrm{~s}^{-1}\end{array}$ \\
\hline$\phi$ & Quantum yield of fluorescence [\%] \\
\hline$\phi_{\text {sat }}$ & Satellite-based NPQ-corrected quantum yield of fluorescence [\%] \\
\hline $\mathrm{qE}$ & Energy-dependent non-photochemical quenching [dimensionless] \\
\hline qI & Reaction center non-photochemical quenching [dimensionless] \\
\hline$S$ & $\begin{array}{l}\text { Correction factor accounting for satellite viewing geometry, } \\
\text { attenuation in the water column of downwelling solar radiation and } \\
\text { upwelled fluoresced light, } \\
\text { differences between the MODIS fluorescence detection band and } \\
\text { the chlorophyll emission spectrum, the fraction of isotropically } \\
\text { emitted fluorescence propagating in the upward direction, and the } \\
\left.\text { top-of-atmosphere irradiance [mW cm } \mathrm{mm}^{-2} \mu \mathrm{m}^{-1} \mathrm{sr}^{-1}\right]\end{array}$ \\
\hline
\end{tabular}

Acknowledgements. We wish to thank J. Ru Morrison, two anonymous reviewers, and J. Cullen for helpful comments on our manuscript. This work was supported by grants from the NASA Ocean Biology and Biogeochemistry Program and the NSF Biological Oceanography Program.

Edited by: A. Bricaud

\section{References}

Abbott, M. R. and Letelier, R.M.: Algorithm theoretical basis document chlorophyll fluorescence, MODIS product number 20, NASA, http://modis.gsfc.nasa.gov/data/atbd/atbd_ $\bmod 22 . p d f, 1999$.

Ahn, Y-H. and Shanmugam, P.: Derivation and analysis of the fluorescence algorithms to etimate phytoplankton pigment concentration in optically complex coastal waters, J. Opt. A-Pure Appl. Opt., 9, 352-362, 2007.
Babin, M., Morel, A. and Gentili, B.: Remote sensing of sea surface sun-induced chlorophyll fluorescence: consequences of natural variations in the optical characteristics of phytoplankton and the quantum yield of chlorophyll a fluorescence, Int. J. Remote Sens., 17, 2417-2448, 1996.

Bailey, S. and Grossman, A.: Photoprotection in Cyanobacteria: Regulation of Light Harvesting, Photochem. Photobiol, 84, 1410-1420, 2008.

Bailey, S., Melis, A., Mackey, K. R. M., Cardol, P., Finazzi, G., van Dijken, G., Berg, G. M., Arrigo, K., Shrager, J., and Grossman, A. Alternative photosynthetic electron flow to oxygen in marine, Synechococcus. Biochim. Biophys. Acta-Bioenerg., 1777, 269 276, 2008.

Barber, J.: Photoinactivation of the isolated photosystem two reaction centre and its prevention, in: Light Biology and Medicine, edited by: Douglas, R. H., Moan, J., and Ronto, G., Plenum Press, New York, 21-32, 1991.

Barber, J. and Andersson, B.: Too much of a good thing: light can be good and bad for photosynthesis, Trends Biochem. Sci., 17 61-66, 1992

Behrenfeld, M. J., Prasil, O., Kolber, Z. S., Babin, M. and Falkowski, P. G.: Compensatory changes in photosystem II electron turnover rates protect photosynthesis from photoinhibition, Photosynth. Res., 58, 259-268, 1998.

Behrenfeld, M. J. and Kolber, Z. S.: Widespread iron limitation of phytoplankton in the south Pacific ocean, Science, 283, 840-843, 1999.

Behrenfeld, M. J. Randerson, J. T., McClain, C. R., Feldman, G C., Los, S., Tucker, C., Falkowski, P.G., Field, C.B., Frouin, R. Esaias, W., and Kolber, D. and Pollack, N.: Biospheric primary production during an ENSO transition, Science, 291, 2594-2597, 2001.

Behrenfeld, M. J. O’Malley, R., Siegel, D. A., McClain, C. R.,Sarmiento, J. L., Feldman, G. C., Milligan, A. J., Falkowski, P. G., Letelier, R. and Boss, E. S.: Climate-driven trends in contemporary ocean productivity, Nature, 444, 752-755, 2006a.

Behrenfeld, M. J., Worthington, K., Sherrell, R. M., Chavez, F. P., Strutton, P., McPhaden, M., and Shea, D. M.: Controls on tropical Pacific Ocean productivity revealed through nutrient stress diagnostics, Nature, 442, 1025-1028, $2006 \mathrm{~b}$.

Behrenfeld, M. J., Halsey, K. and Milligan, A. J.: Evolved physiological responses of phytoplankton to their integrated growth environment, Phil. Trans. Royal Soc. B, 363, 2687-2703, doi:10.1098/rstb.2008.0019, 2008.

Boyd, P. W., Watson, A. J., Law, C. S., et al.: A mesoscale phytoplankton bloom in the polar southern ocean stimulated by iron fertilization, Nature, 407, 695-702, 2000.

Boyd, P. W., Jickells, T., Law, C. S., et al.: Mesoscale iron enrichment experiments 1993-2005: Synthesis and future directions, Science, 315, 612-617, 2007.

Bricaud, A., Babin, M., Morel, A., and Claustre, H.: Variability in the chlorophyll-specific absorption coefficients for natural phytoplankton: Analysis and parameterization, J. Geophys. Res., 100, 13,321-13,332, 1995

Bricaud, A., Morel, A., Babin, M., Allalli, K. and Claustre, H. Variations of light absorption by suspended particles with chlorophyll a concentration in oceanic (case 1) waters: Analysis and implications for bio-optical models, J. Geophys. Res, 103, 31,03331,044, 1998. 
Bruce D and Vasil'ev S: Excess light stress: multiple dissipative processes of excess excitation, in: Chlorophyll a Fluorescence: A Signature of Photosynthesis. Advances in Photosynthesis and Respiration, edited by: Papageorgiou, G. C. and Govindjee, 19, Springer, Dordrecht, Netherlands, 497-523, 2004.

Cardol, P., Bailleul, B., Rappaport, F., Derelle, E., Beal, D., Breyton, C., Bailey, S., Wollman, F. A., Grossman, A., Moreau, H., Finazzi, G.: An original adaptation of photosynthesis in the marine green alga, Ostreococcus, Proc. Natl. Acad. Sci. U. S. A, 105, 7881-7886, 2008.

Cleveland, J. S. and Perry, M. J.: Quantum yield, relative specific absorption and fluorescence in nitrogen limited, Chaetoceros gracilis, Mar. Biol., 94, 489-497, 1987.

Coale, K., Johnson, K. S., Fitzwater, S. E., et al.: A massive phytoplankton bloom induced by an ecosystem-scale iron fertilization experiment in the equatorial Pacific ocean, Nature, 383, 495501, 1996.

Cullen, J. J.: The deep chlorophyll maximum: comparing vertical profiles of chlorophyll a, Can. J. Fish. Aquat. Sci., 39, 791-803, 1982.

Cullen, J. J., Ciotti, Á. M., Davis, R. F., and Neale, P. J.: Relationship between near-surface chlorophyll and solar-stimulated fluorescence: biological effects, Ocean Optics XIII, Proc. SPIE, 2963, 272-277, 1997.

Duysens, L. N. M.: The flattening of the absorption spectra of suspensions as compared to that of solutions, Biochim. Biophys. Acta., 19, 1-12, 1956.

Falkowski, P. G. and Kiefer, D.A.: Chlorophyll a fluorescence in phytoplankton: Relationship to photosynthesis and biomass, J. Plankton Res., 7, 715-731, 1985.

Falkowski, P. G. and Kolber, Z.: Variations in chlorophyll fluorescence yields in phytoplankton in the world oceans, Aust. J. Plant. Physiol., 22, 341-355, 1995.

Field, C.B., Behrenfeld, M.J., Randerson, J.T., and Falkowski, P.G. Primary production of the biosphere: Integrating terrestrial and oceanic components, Science, 281, 237-240, 1998.

Fitzwater, S. E., Coale, K. H, Gordon, R. M, Johnson, K. S, and Ondrusek, M. E.: Iron deficiency and phytoplankton growth in the equatorial Pacific, Deep-Sea Res. II, 43, 995-1015, 1996.

Garcia, H. E., Locarnini, R. A., Boyer, T. P. and Antonov, J. I.: World Ocean Atlas 2005, in: Nutrients (phosphate, nitrate, silicate), Volume 4, edited by: Levitus, S., NOAA Atlas NESDIS 64, US Government Printing Office, Washington, DC, USA, 396 pp., 2006.

Gilerson, A., Zhou, J., Hlaing, S., Ioannou, I., Schalles, J., Gross, B., Moshary, F., and Ahmed, S.: Fluorescence component in the reflectance spectra from coastal waters, Dependence on water composition, Opt. Express., 15, 15, 702-15, 720, 2007.

Gilerson, A., Zhou, J., Hlaing, S., Ioannou, I., Gross, B., Moshary, F., and Ahmed, S.: Fluorescence component in the reflectance spectra from coastal waters II, Performance of retrieval algorithms, Opt. Express., 16, 2446-2460, 2008.

Gordon, H. R. and Wang, M.: Retrieval of water-leaving radiance and aerosol optical thickness over the oceans with SeaWiFS: A preliminary algorithm, Appl. Optics, 33, 443-452, 1994.

Govindjee: Chlorophyll a fluorescence: a bit of basics and history, in: Chlorophyll a Fluorescence: A Signature of Photosynthesis, edited by: Papageorgiou G. C., Dordrecht, the Netherlands, Springer, 1-42, 2004.
Gower, J. F. R. and Borstad, G. A.: Mapping of phytoplankton by solar-stimulated fluorscence using an imaging spectrometer., Int. J. Remote. Sens., 11, 313-320, 1990.

Gower, J. F. R., Brown, L., and Borstad, G. A.: Observation of chlorophyll fluorescence in west coast waters of Canada using the MODIS satellite sensor, Can. J. Remote Sensing, 30, 17-25, 2004.

Gower, J. F. R. and King, S.: Validation of chlorophyll fluorescence derived from MERIS on the west coast of Canada, Intern. J. Remote Sens., 28, 625-635, 2007.

Gregg, W. W., Casey, N. W. and McClain, C. R.: Recent trends in global ocean chlorophyll, Geophys. Res. Lett., 32, L03606, doi:10.1029/2004GL021808, 2005.

Halsey, K. H., Milligan, A., and Behrenfeld, M.J.: The new zscheme of primary production, Photosyn. Res., in review, 2009.

Hu, C., Muller-Karger, F. E., Taylor, C. J., Carder, K. L., Kelble, C., Johns, E. and Heil, C. A.: Red tide detection and tracing using MODIS fluorescence data: A regional example in SW Florida coastal waters, Remote Sens. Environ., 97, 311-321, 2005.

Huot, Y., Brown, C. A. and Cullen, J. J.: New algorithms for MODIS sun-induced chlorophyll fluorescence and a comparison with present data products, Limnol. Oceanogr. Methods, 3, 108130, 2005.

Huot, Y., Brown, C. A. and Cullen, J. J.: Retrieval of phytoplankton biomass from simultaneous inversion of reflectance, the diffuse attenuation coefficient, and sun-induced fluorescence in coastal waters, J. Geophys. Res., 112, C06013, doi:10.1029/2006JC003794, 2007.

Ivanov, A. G., Park, Y.-I., Miskiewicz, E., Raven, J. A., Huner, N. P. A., and Öquist, G.: Iron stress restricts photosynthetic intersystem electron transport in Synechococcus sp. PCC 7942, FEBS Lett., 485, 173-177, 2000.

Jassby, A. D. and Platt, T.: Mathematical formulation of the relationship between photosynthesis and light for phytoplankton, Limnol. Oceanogr., 21, 540-547, 1976.

Kiefer, D. A.: Fluorescence properties of natural phytoplankton populations, Mar. Biol., 22, 263-269, 1973a.

Kiefer, D. A.: Chlorophyll a fluorescence in marine centric diatoms: responses of chloroplasts to light and nutrient stress, Mar. Biol., 23, 39-46, 1973b.

Kiefer, D. A., Chamberlin, W. S. and Booth, C. R.: Natural fluorescence of chlorophyll a: Relationship to photosynthesis and chlorophyll concentration in the western South Pacific gyre, Limnol. Oceanogr., 34, 868-881, 1989.

Kistler, R., Kalnay, E., Collins, W., et al.: The NCEP-NCAR 50year reanalysis: Monthly means CD-ROM and documentation, Bull. Amer. Meteorol. Soc., 82, 247-267, 2001.

Kok, B.: On the inhibition of photosynthesis by intense light, Biochim. Biophys. Acta, 21, 234-244, 1956.

Krause, G. H. and Weis, E.: Chlorophyll fluorescence and photosynthesis: the basics, Annu. Rev. Plant Phys. Plant Mol. Biol., 42, 313-349, 1991.

Krause, G. H. and Jahns, P.: Non-photochemical energy dissipation determined by chlorophyll fluorescence quenching: Charcterization and function, in: Chlorophyll a fluorescence: A signature of photosynthesis, edited by: Papageorgiou, G. C. and Govindjee, Springer, Dordrecht, The Netherlands, 463-495, 2004.

Kruskopf, M. and Flynn, K. J.: Chlorophyll content and fluorescence responses cannot be used to gauge reliably phytoplankton 
biomass, nutrient status or growth rate, New Phytol., 169, 52536, 2006

Kyle, D.J.: The biochemical basis of photoinhibition of photosystem II, in: Photoinhibition, edited by: Kyle, D. J., Osmond, C. B., and Arntzen, C. J., Elsevier, Amsterdam, 197-226, 1987.

Laney, S. R., Letelier, R. M., and Abbott, M. R.: Parameterizing the natural fluorescence kinetics of Thalassiosira weissflogii, Limnol. Oceanogr., 50, 1499-1510, 2005.

Letelier, R. M., Abbott, M. R. and Karl, D. M.: Chlorophyll natural fluorescence response to upwelling events in the Southern Ocean, Geophys. Res. Lett., 24, 409-412, 1997.

Loftus, M. E. and Seliger, H. H.: Some limitations of the in vivo fluorescence technique, Chesapeake Sci., 16, 79-92, 1975.

Lorenzen, C. J.: A method for the continuous measurement of in vivo chlorophyll concentration, Deep-Sea Res., 13, 223-227, 1966.

Luo, C., Mahowald, N., and Corral, J. D.: Sensitivity study of meteorological parameters on mineral aerosol mobilization, transport and distribution, J. Geophys. Res., 108, 4447, doi:10.1029/2003JD0003483, 2003.

Luo, C., Mahowald, N. M., Meskhidze, N., et al.: Estimation of iron solubility from observations and a global aerosol model, J. Geophys. Res., 110, D23307, doi:10.1029/2005JD006059, 2005.

Luo, C., Mahowald, N., Bond, T., et al.: Combustion iron distribution and deposition, Global Biogeochem. Cy., 22,GB1012, doi:10.1029/2007GB002964, 2008.

Mahowald, N., Luo, C., Corral, J. D., and Zender, C.: Interannual variability in atmospheric mineral aerosols from a 22-year model simulation and observational data, J. Geophys. Res., 108, 4352, doi:10.1029/2002JD002821, 2003.

Mackey, K. R. M., Paytan, A., Grossman, A. R., and Bailey, S.: A photosynthetic strategy for coping in a high-light, low-nutrient environment, Limnol. Oceanogr., 53, 900-913, 2008.

Maritorena, S., Morel, A., and Gentili, B.: Determination of the fluorescence quantum yield by oceanic phytoplankton in their natural habitat, Appl. Optics, 39, 6725-6737, 2000.

Martin, J. H. and Fitzwater, S. E.: Iron deficiency limits phytoplankton growth in the north-east Pacific subarctic, Nature, 331, 341-343, 1988.

Martin, J.H. Glacial-interglacial $\mathrm{CO}_{2}$ change: The iron hypothesis, Paleoceanography, 5, 1-13, 1990.

Martin, J. H, Gordon, R. M., and Fitzwater, S. E.: The case for iron, Limnol. Oceanogr., 36, 1793-1802, 1991.

Martin, J., Coale, K., Johnson, K. S., et al.: Testing the iron hypothesis in ecosystems of the equatorial Pacific ocean, Nature, 371, 123-129, 1994.

Moore, J. K. and Braucher, O.: Sedimentary and mineral dust sources of dissolved iron to the world ocean, Biogeosciences, 5, 631-656, 2008, http://www.biogeosciences.net/5/631/2008/.

Moore, J. K., Doney, S. C., Lindsay, K., Mahowald, N. and Michaels, A. F.: Nitrogen fixation amplifies the ocean biogeochemical response to decadal timescale variations in mineral dust deposition, Tellus, 58B, 560-572, 2006.

Morel, A. and Prieur, L.: Analysis of variations in ocean color, Limnol. Oceanogr., 22, 709-722, 1977.

Morrison, J. R.: In situ determination of the quantum yield of phytoplankton chlorophyll fluorescence: A simple algorithm, observations, and model, Limnol. Oceanogr., 48, 618-631, 2003.
Müller, P., Li, X-P. and Niyogi, K. N.: Non-photochemical quenching, A response to excess light energy, Plant Physiol., 125, 15581566, 2001.

Neville, R. A. and Gower, J. F. R.: Passive remote sensing of phytoplankton via chlorophyll a fluorescence, J. Geophys. Res., 82, 3487-3493, 1977.

Osmond, C. B.: What is photoinhibition? Some insights from comparisons of shade and sun plants, in: Photoinhibition of Photosynthesis: From Molecular Mechanisms to the Field, edited by: Baker, N. R. and Bowyer, J. R., BIOS Scientific Publisher, Oxford, UK, 1-24, 1994.

Ostrowska, M., Darecki, M., and Wozniak, B.: An attempt to use measurements of sun-induced chlorophyll fluorescence to estimate chlorophyll a concentration in the Baltic Sea, Proc. Spie Int. Soc. Opt. Eng., 3222, 528-537, 1997.

Parkhill, J.-P., Maillet, G., and Cullen, J. J.: Fluorescence-based maximal quantum yield for PSII as a diagnostic of nutrient stress, J. Phycol., 37, 517-529, 2001.

Prasil, O., Adir, N., and Ohad, I.: Dynamics of photosystem II: mechanism of photoinhibition and recovery processes, in: The Photosystems: Structure, Function and Molecular Biology, edited by: Barber, J., Elsevier, Amsterdam, 295-348, 1992.

Rueter, J.G. and Ades, D. R.: The role of iron nutrition in photosynthesis and nitrogen assimilation in Scenedesmus quadricauda (Chlorophyceae), J. Phycol., 23, 452-457, 1987.

Sakshaug, E. and Holm-Hansen, O.: Chemical composition of Skeletonema costatum (Greve), Cleve and Pavlova (Monochrysis) lutheri (Droop) Green As a function of nitrate-, phosphate-, and iron-limited growth, J. Exp. Mar. Biol. Ecol., 29, 1-34, 1977.

Sandmann, G.: Consequences of iron deficiency on photosynthetic and respiratory electron transport in blue-green algae, Photosynth. Res., 6, 261-271, 1985.

Schallenberg, C., Lewis, M. R., Kelley, D. E., and Cullen, J. J.: Inferred influence of nutrient availability on the relationship between Sun-induced chlorophyll fluorescence and incident irradiance in the Bering Sea, J. Geophys. Res., 113, C07046, doi: 10.1029/2007JC004355, 2008.

Schneider, B., Bopp, L., Gehlen, M., Segschneider, J., Frölicher, T. L., Cadule, P., Friedlingstein, P., Doney, S. C., Behrenfeld, M. J., and Joos, F.: Climate-induced interannual variability of marine primary and export production in three global coupled climate carbon cycle models, Biogeosciences, 5, 597-614, 2008, http://www.biogeosciences.net/5/597/2008/.

Strzepek, R. F. and Harrison, P. J.: Photosynthetic architecture differs in coastal and oceanic diatoms, Nature, 43, 689-692, 2004.

Thomas, W. H. and Dodson, A. N.: On nitrogen deficiency in tropical Pacific oceanic phytoplankton, II, Photosynthetic and cellular characteristics of a chemostat-grown diatom, Limnol. Oceanogr., 17, 515-523, 1972.

Topliss, B. J. and Platt, T.: Passive fluorescence and photosynthesis in the ocean: implications for remote sensing, Deep-Sea Res., 33, 849-864, 1986.

Tsuda, A., Takeda, S., Saito, H., et al.: A mesoscale iron enrichment in the western Subarctic Pacific induces a large centric diatom bloom, Science, 300, 958-961, 2003.

Vassiliev, I. R., Kolber, Z., Wyman, K. D., et al.: Effects of iron limitation on photosystem II composition and light utilization in Duneliella tertiolecta, Plant Physiol., 109, 963-972, 1995.

Vincent, W. F.: Mechanisms of rapid photosynthetic adaptation 
in natural phytoplankton communities, I, Redistribution of excitation energy between photosystems I and II, J. Phycol., 15, 429-434, 1979.

Wagener, T., Guieu, C., Losno, R., Bonnet, S., and Mahowald, N.: Revisiting atmospheric dust export to the Southern Ocean: Biogeochemical implications, Global Biogeochem. Cy., 22, GB2006, doi:10.1029/2007GB002984, 2008.

Westberry T. K. and Siegel, D.A.: Phytoplankton natural fluorescence in the Sargasso Sea: Prediction of primary production and eddy induced nutrient fluxes, Deep-Sea Research Pt. I, 50, 417434, 2003.

Wiggert, J. D., Murtugudde, R. G., and Christian, J. R.: Annual ecosystem variability in the tropical Indian Ocean: Results from a coupled bio-physical ocean general circulation model, DeepSea Res. Pt. II, 53, 644-676, 2006.

Wiggert, J. D. and Murtugudde, R. G. The sensitivity of the southwest monsoon phytoplankton bloom to variations in aeolian iron deposition over the Arabian Sea, J. Geophys. Res., 112,C05005, doi:10.1029/2006JC003514, 2007.

Young, E. B. and Beardall, J.: Photosynthetic function in Dunaliella tertiolecta (Chlorophyta) during a nitrogen starvation and recovery cycle, J. Phycol., 39, 897-905, 2003.

Zender, C., Bian, H., and Newman, D.: Mineral dust entrainment and deposition (DEAD) model: Description and 1990s dust climatology, J. Geophys. Res., 108, 4416, doi:10.1029/2002JD002775, 2003.

\section{Additional References in Appendix A}

Behrenfeld, M. J., Boss, E. S., Siegel, D. A., and Shea, D. M.: Carbon-based ocean productivity and phytoplankton physiology from space, Global Biogeochem. Cy., 19, GB1006, doi:10.1029/2004GB002299, 2005.

Carder, K. L., Chen, R., and Hawes, S.: Algorithm theoretical basis document ATBD 20: Instantaneous photosynthetically available radiation and absorbed radiation by phytoplankton, NASA, version 7, http://modis.gsfc.nasa.gov/data/atbd/atbd_mod20.pdf, 2003.

Collins, D. J., Kiefer, D. A., Soohoo, J. B., and McDermid, I. S.: The role of reabsorption in the spectral distribution of phytoplankton fluorescence emission, Deep-Sea Res., 32, 983-1003, 1985.

Gordon, H. R. and Voss, K. J.: Algorithm theoretical basis document normalized Water leaving Radiance, MOD 18, http:// modis.gsfc.nasa.gov/data/atbd/atbd_mod18.pdf, NASA, 1999.

Huot, Y., Brown, C. A., and Cullen, J. J.: New algorithms for MODIS sun-induced chlorophyll fluorescence and a comparison with present data products, Limnol. Oceanogr., 3, 108-130, 2005.

Lee, Z. P., Carder, K. L., and Arnone, R.: Deriving inherent optical properties from water color: A multi-band quasi-analytical algorithm for optically deep waters, Appl. Optics, 41, 5755-5772, 2002.

Maritorena, S., Siegel, D. A., and Peterson, A. R.: Optimization of a semianalytical ocean color model for global-scale applications, Appl. Optics, 41, 2705-2714, 2002.

Mobley, C. D.: Light and Water: Radiative Transfer in Natural Waters, Academic, San Diego, California, USA, 592 pp. 1994.

Thuillier, G., Hersé, M., Simon, P. C., Labs, D., Mandel, H., Gillotay, D., and Foujols, T.: The solar spectral irradiance from 200 to $2400 \mathrm{~nm}$ as measured by the SOLSPEC spectrometer from the ATLAS 1-2-3 and EURECA missions, Sol. Phys., 214, 1-22, 2003.

Westberry, T. K., Behrenfeld, M. J., Siegel, D. A., Boss, E.: Carbon-based primary productivity modeling with vertically resolved photoacclimation, Global Biogeochem. Cy., 22, GB2024, doi:10.1029/2007GB003078, 2008. 